\title{
Simple solutions for the summer shallow atmospheric circulation
}

\section{over North Africa}

\author{
G.A. Dalu ${ }^{\mathrm{a}}$, M. Gaetani ${ }^{\mathrm{b}}$, C. Lavaysse $^{\mathrm{c}}$, C. Flamant $^{\mathrm{b}}$, A.T. Evan ${ }^{\mathrm{d}}$, M. Baldi ${ }^{\mathrm{a}}$ \\ ${ }^{\mathrm{a}}$ CNR-BIMET, Rome, Italy ${ }^{\mathrm{b}}$ LATMOS-IPSL, Universite Pierre et Marie Curie, Paris, France ${ }^{\mathrm{c}}$ European Commission, Joint \\ Research Centre, Ispra, Italy ${ }^{\mathrm{d}}$ Scripps Institution of Oceanography, Univ. of California San Diego, La Jolla CA \\ ${ }^{*}$ Correspondence to: M. Baldi, CNR-IBIMET, Via dei Taurini 19, 00185 Rome - Italy E-mail: m.baldi@ibimet.cnr.it
}

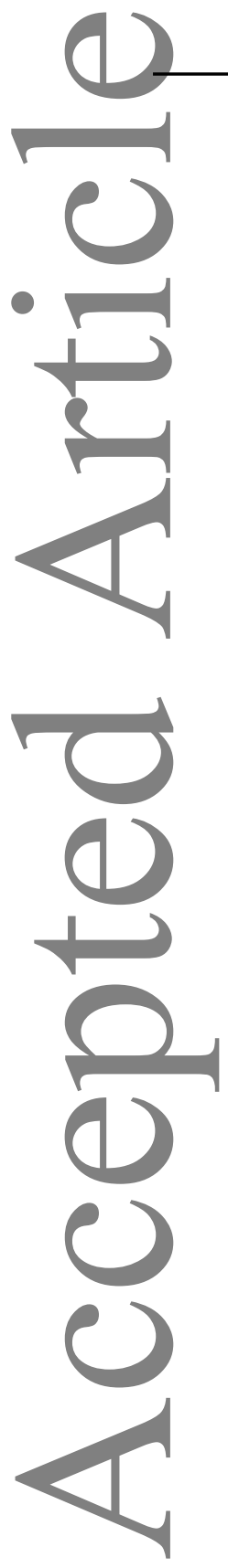

The spring-to-summer shallow atmospheric circulation over North Africa is driven by two desert heat lows (DHLs), one over Sahara (SHL) and one over Arabia (AHL), with cyclones embedded in the convective layer, capped by mid-tropospheric anticyclones. The aim of this work is to produce a minimal theoretical framework for these dynamical features in terms of Kelvin, mixed and planetary mode solutions to a two-layer MatsunoGill model with a lower Rayleigh frictional layer dynamically coupled to an almost frictionless upper layer. Results show that a DHL drives a Walker-like cell with rising air over the low and subsiding air to its west, with the lower-level cyclone to the east of the mid-tropospheric anticyclone; the latter being bounded to the south-west by an unstable easterly jet. These features, related to frictional differences between the two layers, are enhanced by ambient easterly winds. In spring, the stronger SHL drives a cell with rising air over West Africa and subsiding over the Atlantic. The weaker AHL drives a cell with rising air over Arabia and subsiding over East Africa. In summer, the stronger AHL drives a cell with rising air over Arabia and subsiding over Libya, and the weaker SHL drives a cell with rising air over West Sahara and subsiding over the Atlantic. The concurrent contributions of easterly winds, monsoonal low level convergence, and seasonal airborne dust warming strengthen the SHL, making its winds stronger than those of the AHL. In addition, a third order expansion of the Coriolis parameter strengthens the zonal winds and weakens the meridional winds. These contributors strengthen anticyclones over the East Mediterranean and to the west of Gibraltar. The ability of the model in representing the main features of the North African atmospheric circulations suggests a potential for better understanding climate dynamics in connected regions (Mediterranean, Tropical Atlantic).

Key Whords: North African winds; Desert heat lows; West African high; Libyan high; African easterly jet; Instability regions

This article has been accepted for publication and undergone full peer review but has not been through the copyediting, typesetting, pagination and proofreading process, which may lead to differences between this version and the Version of Record. Please cite this article as doi: $10.1002 /$ qj.3246 


\section{Introduction}

North Africa is characterized by complex climate and geographical features, which occur in a span of $15^{\circ}-20^{\circ}$ of latitude $(1500-2000 \mathrm{~km})$. Equatorial rain forests, followed by semiarid shrublands and rocky and sand bare deserts, add specific features to the North African shallow atmospheric dynamics. The maximum complexity is reached during boreal summer, when the north African continent and the Mediterranean region are under the monsoonal influence (Chen 2003; Rodwell and Hoskins, 1996; 2001); this is when a fully developed West African monsoon (WAM) interacts with the shallow circulation driven by the desert heat lows (DHLs), and when this circulation influences the hurricane season in the Tropical Atlantic (Landsea and Gray, 1992).

The spring-to-summer evolution of the shallow atmospheric circulation is deeply tied to the DHLs, which strengthen and split in two lows in late spring and summer as shown in Fig. 1 and Fig. 2. In spring, the Saharan heat low (SHL) is larger than the Arabian at low (AHL) (Fig. 1a). On the contrary, in summer, the AHL is larger than the SHL (Fig. 2a). The intense near-surface heat in 1. these DHLs is accompanied by cyclones, convergence and rising motions, which contrast with upper-level anticyclones, divergence and subsidence. The zonal cross section of the DHL circulations shows that air rises from the heat low and subsides to its west, generating a zonal circulation confined within the lower half of the troposphere (Fig. 1b and Fig. 2b). The main difference between these Walker-like circulations and the Walker circulation is that the subsidence occurs to the west of the DHL, while in the Walker cell the subsidence occurs to the east of the warm pool.

The prevailing zonal structure of the shallow atmospheric circulation over $\mathrm{N}$ Africa clearly shows in ERA-40 and NCEP1 and NCEP2 reanalysis, see figures 21 and 22 in Zhang et al. (2008). In addition, the meridional outflow is maximum in spring and minimum in summer, but in both seasons the upper-level southward outflow is not sufficiently strong to compensate the lower-level northward inflow in Abidjan (at the Guinea coast) and in Dakar (to the north of WAM and the south of DHL), see figures 4 and 6 in Zhang et al. (2008). In this work, it will be shown that article is protected by compright All rights reserved due to the presence of mixed waves in-phase with the diabatic forcing and to the presence of westward decaying planetary waves.

Chen (2005) presented a comprehensive picture of the complex summer tropospheric circulation over North Africa, by reporting its essential ingredients: (1) a cyclone in the convective layer, driven by a DHL; (2) an upper-level anticyclone, driven by rising motions from the frictional layer and by monsoonal subsidence, and spatially in quadrature with the lower-level cyclone (a $\pi / 2$ phase shift in the zonal direction); (3) a mid-tropospheric jet, almost in geostrophic balance.

The DHL activity interacts with the perturbations which travel westward across North Africa, playing a crucial role in the regional climate variability (Lavaysse et al. 2009; 2010a). Moreover, DHL dynamics are modulated by midlatitude intrusion of synoptic disturbances (Chauvin et al. 2010), and northerly advection of cold air and moisture from the Mediterranean region (Vizy and Cook 2009; Gaetani et al. 2010; Evan et, 2015); in addition, the lower-level cyclonic winds favor the transport of moist air masses across North Africa from the North Atlantic (Lavaysse et al. 2010b) and the Mediterranean (Peyrillé and Lafore 2007), modulating the distribution of the WAM precipitation across the Sahel (Lavaysse et al. 2010b and 2015). Biasutti et al. (2009) have identified the SHL as a key element controlling the Sahelian rainfall. These perturbations, which travel westward with the African easterly waves (AEWs), are generated by barotropic and baroclinic instabilities of the African easterly jet (AEJ) (Thorncroft and Hoskins 1994a, 1994b; Wu et al. 2012; Cook, 2015). In addition of playing a crucial role on the monsoonal precipitation (Gu et al. 2004; Skinner and Diffenbaugh 2013), the AEWs are important in the development of tropical cyclones (Thorncroft and Hodges, 2001; Price et al 2015). The easterly jet, which acts as a waveguide for the AEWs, is maintained by meridional temperature gradients (Cook 1999, Wu et al. 2009), and is strengthened by the monsoonal subsidence and by radiative cooling (Schubert et al, 1991; Thorncroft and Blackburn, 1999; Chen 2005).

This work is an analysis of the seasonal features of the shallow atmospheric circulation over North Africa based on the solutions to a Matsuno-Gill model-system (Matsuno, 1966; Gill, 1980), obtained by dynamically coupling a dissipative lower mixed 
layer (Neelin, 1989; Stevens at al, 2002) with an upper almost frictionless layer of equal depth (Vallis, 2010). This frictional difference overcomes the limitations related to uniform frictional losses in Gill's model (Rodwell and Hoskins, 1996).

In this work, the dynamics are forced by prescribed diabatic buoyancy sources, which generate rising motions in the lower layer, mass balanced by subsiding motions in the upper layer. These motions are confined within the lower half of the troposphere by a lid placed at the mid-tropospheric level (Fig. 3). The environment parameters are tuned in order to reproduce the main dynamical features in a consistent manner with observations and more complex model studies (see Thorncroft and Blackburn 1999; Cook 1999; Chen 2005; Lavaysse et al. 2009).

It will be shown that the presence of an upper almost frictionless layer capped by a mid-tropospheric lid are essential ingredients for the westward displacement of the upper-level Libyan high in two-layer with the AHL and of the West African high (WAH) in respect of the SHL. These displacements are strictly related to the subsidence over the Libyan desert and over the Tropical Atlantic. The subsidence regions zonally widen in the esence of easterly winds.

Since recent studies have shown a non negligible contribution by the Arabian heat low to the AEJ (Spinks et al. 2015; Spinks and Lin 2015), and that the development of the SHL is concomitant with the development of the West African Monsoon (WAM), and with the Saharan dust emission peak (Engelstaedter et al. 2006), he influence of these contributors on the African winds is also analyzed.

The scope of this work is to provide a theoretical basis in terms of Kelvin, mixed gravity-planetary and planetary modes for analyzing important dynamical features, such as the contribution by the desert heat lows to the dynamics of the shallow atmospheric circulation, the zonal quadrature between the high and the low pressure systems, the behavior of the AEJ, the strengthening of the Libyan anticyclone and of the subsidence over the Tropical Atlantic. Given the complexity of the problem, this work aims to the construction of a minimal analytic mathematical theory, which swiftly allows the description of the main features in terms of basic dyhis article is protected by copyright All rights reseryed. assessing the impacts in nearby, connected regions, such as the Sahel, the Mediterranean and the Tropical Atlantic.

This paper is organized as follows: the model is presented in section 2; the seasonal DHLs are introduced in section 3; the spring shallow atmospheric circulation is analyzed in section 4; the summer circulation is analyzed in section 5, and this section includes subsections where the contributions by ambient and monsoonal winds and desert dust warming are also analyzed; the conclusions are drawn in section 6. Finally, the mathematical solutions to the model-system are discussed in the Appendix.

\section{Matsuno-Gill model}

The dynamics in the lower half of the troposphere are studied by using a two-layer model system in the shallow water approximation, where the frictional losses are large in layer $\mathbf{2}$ and small in layer $\mathbf{1}$, with vanishing vertical velocity at top and bottom of the model system, and continuous vertical velocity at the interface between the two layers (see Fig. 3). Using Gill's model formulation by Phlips and Gill (1987) and omitting the layer indexing, the governing equations are,

$$
\left\{\begin{array}{l}
\left(\epsilon+U \partial_{x}\right) q+\partial_{x} q+\left(\partial_{y}-\frac{1}{2} y\right) v=-Q \\
\left(\epsilon+U \partial_{x}\right) r-\partial_{x} r+\left(\partial_{y}+\frac{1}{2} y\right) v=-Q \\
2\left(\epsilon+U \partial_{x}\right) v+\left(\partial_{y}+\frac{1}{2} y\right) q+\left(\partial_{y}-\frac{1}{2} y\right) r=0
\end{array}\right.
$$

The dynamics are forced by a buoyancy source $Q$ (positive for warming). In these equations $q=\phi+u$ and $r=\phi-u$, where $\phi$ is pressure and $u$ is the zonal momentum component, $v$ is the meridional momentum component, $U$ is the ambient wind, and $f=\frac{1}{2} y$ is the Coriolis parameter) in the equatorial $\beta$-plane. The following equivalences have been used, $\left(\frac{\partial}{\partial x}, \frac{\partial}{\partial y}, \frac{d}{d x}, \frac{d}{d y}\right) \equiv$ $\left(\partial_{x}, \partial_{y}, \mathcal{D}_{x}, \mathcal{D}_{y}\right)$. As in Gill's original work, the coordinates and variables are non-dimensional $\left(x^{\prime}=\frac{x}{R_{0}}, y^{\prime}=\frac{y}{R_{0}}\right)$ and $\left(u^{\prime}=\frac{u}{c}, v^{\prime}=\frac{v}{c}, U^{\prime}=\frac{U}{c}, \epsilon^{\prime}=\tau \epsilon\right),\left(\phi^{\prime}=\frac{\phi}{c^{2}}, Q^{\prime}=\frac{Q}{c^{2}}\right)$ with the primes dropped, where $R_{0}$ is the equatorial Rossby radius, $c$ is the long gravity wave phase speed, $\epsilon$ is the frictional Rayleigh time, and $\tau=R_{0} / c$. The solutions to the above equations, given 
in the Appendix, are constructed as in the work by Phlips and Gill (1987).

\subsection{Lid}

The vertical confinement of the motions seen in Fig. 1b and Fig. $2 \mathrm{~b}$ is obtained by placing a lid at the mid-tropospheric level. In the absence of this lid, the vertical velocity at the top of the model yould be $\Delta w=\left(w_{1}+w_{2}\right)$, where $w_{1}=\left[\left(\epsilon_{1}+U_{1} \partial_{x}\right) \phi_{1}-Q\right]$ and $w_{\mathbf{2}}=\left[\left(\epsilon_{\mathbf{2}}+U_{\mathbf{2}} \partial_{x}\right) \phi_{\mathbf{2}}+Q\right]$ are the vertical velocities in

layer $\mathbf{1}$ and $\mathbf{2}$; these velocities are obtained by using the continuity equation (2.5) in Gill (1980), where $\partial_{t}$ has been replaced by $\left(\epsilon+U \partial_{x}\right)$. Then, for vanishing vertical velocities, the lid reaction s yielded by the solution to the following equation,

$$
\left(\bar{\epsilon}+\bar{U} \partial_{x}\right) \phi_{L i d}=-\left(w_{\mathbf{1}}+w_{\mathbf{2}}\right)
$$

where $\bar{\epsilon}=\left(\epsilon_{\mathbf{1}}+\epsilon_{\mathbf{2}}\right) / 2$ and $\bar{U}=\left(U_{\mathbf{1}}+U_{\mathbf{2}}\right) / 2$. The lid reaction, by acting with equal strength on both layers, drives a barotropic mode, which is anticyclonic in regions of prevailing subsidence, $\phi_{\text {Lid }}>0$ where $\left(w_{\mathbf{1}}+w_{\mathbf{2}}\right)<0$.

\section{Spring-to-summer heat lows}

In late spring the heat low located over West Africa is larger and deeper than the low located over the Arabian peninsula; while, in summer the SHL is smaller and shallower than the AHL, see Fig. 1a and Fig. 2a. These heat lows are introduced in the model system as spatially confined buoyancy sources (positive for warming), $Q(x, y)=I Q \sin \left[k\left(x-x_{0}\right)\right] \cos \left[\lambda\left(y-y_{0}\right)\right]$ with $k L_{x}=\pi$ and $\lambda L_{y}=\frac{\pi}{2}$, for $0 \leq\left[k\left(x-x_{0}\right)\right] \leq \pi$ and $\mid \lambda(y-$ $\left.y_{0}\right) \mid \leq \frac{\pi}{2}$, else $Q(x, y)=0$. In dimensional units, $Q$ is taken proportional to the diabatic potential temperature perturbation, $I Q=\epsilon_{N} g \Delta \theta_{D} / \Theta_{0}$, where $\epsilon_{N}^{-1}$ is the Newtonian relaxation time (Neelin, 1989).

When $Q>0$, a fraction of the lower layer fluid is displaced into the upper layer, and thus the heating is a mass sink for the lower layer and a mass source for the upper layer. In two-layer models, each layer is isentropic, and temperature perturbations are interface perturbations. The diabatic interface depression, $-g \eta_{D}=g h \Delta \theta_{D} / \Theta_{0}$, drives the lower-level convergence and the upper-levei article is protected by copyright thill rights reserved. represented by the gravest mode to make the results more readable in terms of the solutions to Eq. (1). Flow details (not included in this work) could be simulated by adding higher order modes, as it has been done by Zhang and Krishnamurti (1996) in their study of the Gill's heat induced tropical circulation.

In order to reduce the PDE system in (1) into the ODE system in (5), the source is expanded in terms of parabolic cylindrical functions $Q(x, y)=\sin \left[k\left(x-x_{0}\right)\right] \sum_{n=0,1 \ldots} Q_{n} D_{n}(y) ; Q_{n}$ and $Q_{n} D_{n}(y)$ are shown in Fig. 4a. The indexing in this section refers to the order of $D_{n}(y)$ and its coefficients $Q_{n}$.

The spring spectrum is shifted toward lower order spectral lines with respect to the summer spectrum (Fig. 4a). It results that the spring source components are confined within the tropics (Fig. 4b); while the summer components overboard into the near extratropics (Fig. 4c). Since the dynamics is made of Kelvin modes excited by $Q_{0}$, mixed modes excited by $Q_{1}$, and planetary modes excited by $Q_{n \geq 1}$, the seasonal dynamical response can be inferred by inspecting the related source spectrum, because Kelvin waves drive the dynamics to the east of the source, while mixed wave dynamics are in phase with the source, and planetary waves drive the dynamics to the west of the source (Gill, 1980; Rodwell and Hoskins, 2001).

\subsection{Environment parameters}

The two layers have an equal depth, $h$; the total depth is $H=$ $2 h$, taken equal to half of the tropospheric depth. The Rossby radius $R_{0}$ is taken equal to 6 [degrees] in both layers, $c=\frac{R_{0}^{2}}{2 \beta}$ is the long gravity wave speed, $g^{\prime}=\frac{c^{2}}{h}=g \frac{\Delta \Theta}{\Theta}=-g \frac{\Delta \rho}{\rho}$ is the reduced gravity, where $\Delta \Theta$ is the potential temperature and $-\Delta \rho$ is the density difference between the two layers, and $\Theta$ and $\rho$ are reference potential temperature and density, respectively. $\tau=$ $\left(\frac{R_{0}}{c}\right) \approx 0.4$ [day] is the characteristic time of the flow; since we are interested in times $t>>\tau, \partial_{t}$ has been neglected in the model equations.

In Gill's classic model, the frictional and the Newtonian relaxations time are equal to 2 [days]; it results that the flow is symmetrically specular about its mid-level, with an upper-level anticyclone and a lower-level cyclone of equal intensity.

In multi-layer models, these times range from about a day in the lower layers to about 30 days in the upper layers (Rodwell and 
Hoskins, 2001). In this two-layer model, we take $\epsilon_{\mathbf{2}}^{-1}=\epsilon_{N}^{-1}=2$ [days] in the frictional layer, and $\epsilon_{\mathbf{1}}^{-1}=5 \epsilon_{\mathbf{2}}^{-1}$ in the layer above it. With these parameter values, the position and intensity of the easterly jet in the model are in agreement with those shown by reanalysis data (Fig. 1a,2a).

In addition, we show results in the absence and in the presence of an ambient wind. In the latter case, we take $U_{1}=2 U_{2}=-3$ $[\mathrm{m} / \mathrm{s}]$ for $|y|<30^{\circ}$, and $U_{\mathbf{1}}=2 U_{\mathbf{2}}=3[\mathrm{~m} / \mathrm{s}]$ for $|y|>30^{\circ}$, in a simplified representation of the transition from tropical easterlies to extra-tropical westerlies of the zonally averaged wind.

\section{Spring circulation}

The model spring circulation is analyzed by assuming that the heat low over West Africa, $Q_{S H L}$, is larger than the heat low over the Arabian peninsula, $Q_{A H L}$, as seen in Fig. 1a. The model flow driven by these DHLs is shown in Fig. 5.

Here, the lower-level cyclones are weaker than the upper-level thicyclones, and the upper-level highs are displaced to the west in respect of the lower-level heat lows (compare Fig. 5b with Fig. 5d). An unstable jet flows to the south-west of the respective DHL (Fig. 5b). The vertical velocities at the intermediate level show that the circulation is made of two elongated zonal Walker-like cells (Fig. 5c). In the SHL cell air rises over the Sahara and subsides over the Tropical Atlantic, and, in the AHL cell, air rises over Arabia and subsides over East Africa. The lid reaction, computed using Eq. (2), is shown in Fig. 5a. This reaction drives anticyclonic winds through the depth of the shallow circulation over the subsidence regions.

The subsidence regions are strictly related to the friction differences between the two layers and to lid reaction. This is evident by comparing Fig. 5 with Fig. 6 . In the latter, the model circulation is simulated by assuming that the dissipation coefficient is the same in both layer and equal to that adopted by Gill (1980). Here the flow is specular symmetric about the interface, the lid reaction is absent, the easterly jet is weak and the subsidence over the ocean is almost absent. This comparison shows that uniform dissipative systems do not simulate important

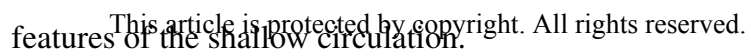

The presence of easterly ambient winds zonally elongates the SHL and AHL cells, displacing the west African high westward and connecting the AHL jet to the SHL jet, as shown in Fig. 7.

In the remaining part of this section, we analyze the main dynamical features in terms of the modes excited by the diabatic source.

\subsection{Analysis of the main features}

The areas of potential instabilities seen in Fig. $5 \mathrm{~b}$ have been evaluated by posing $\Delta u=\left(u_{1}-u_{2}\right) / 2$ and $L_{d}=f^{-1} \sqrt{g^{\prime} H}$, then the area where $|\Delta u|>\frac{1}{4} \beta L_{d}^{2}$ is baroclinically unstable; and by posing $\bar{u}=\left(u_{1}+u_{\mathbf{2}}\right) / 2$ and $\bar{u}_{s}$ its value where $\left(\beta-\partial_{y y} \bar{u}_{s}\right)=$ $0\left(u_{s}\right.$ is the zonal wind at the latitude where the meridional gradient of the absolute vorticity vanishes), then the area where $\left(\beta-\partial_{y y} \bar{u}\right)\left(\bar{u}-\bar{u}_{s}\right)>0$ is barotropically unstable (Vallis, 2010).

In this season, the source strongest spectral lines are the lower order components (Fig. 4a). The gravest mode, $Q_{0}$ (see Eq. 6 in the Appendix), excites those Kelvin waves, which drive the weak flow about the equator to the east of the DHLs. The 1st order component, $Q_{1}$ (see Eq. 7 in the Appendix), excites the mixed gravity-planetary non propagating mode, which forces the south-westerly winds in the Gulf of Guinea region, favoring the penetration of marine air into the interior of the continent. The higher order components, $Q_{n \geq 1}$ (see Eq. 8 in the Appendix), excite westwards propagating planetary waves. For further detailing on the role of the long planetary wave, we construct the $n$th components of the pressure field and of the zonal momentum, obtained by sum and difference of the 1st and 3rd equation in Eq. (8) in the Appendix,

$\left\{\begin{array}{l}\phi_{n}(x, y)=0.5 q_{n+1}(x)\left[D_{n+1}(y)+(n+1) D_{n-1}(y)\right] \\ u_{n}(x, y)=0.5 q_{n+1}(x)\left[D_{n+1}(y)-(n+1) D_{n-1}(y)\right] \\ \left(c_{n}+U\right) \partial_{x} q_{n+1}^{F}+\epsilon q_{n+1}^{F} \propto \sin (k x)\end{array}\right.$

From the 1st and 3rd equation we deduce that these waves decay westerly with an $e$-folding distance equal to $L_{n}=\epsilon^{-1}\left(c_{n}-U\right)$, where $c_{n}=-\left(2 n+1+2 k^{2}\right)^{-1}$ is their phase speed and $k$ is their zonal wavenumber. $L_{n}$ increases with the Rayleigh friction time, 
with easterly ambient winds and with $c_{n}\left(c_{n}\right.$ decreases with $n$, see the Appendix for further details); while it decreases in the presence of westerly ambient winds (Fig. 8a). $L_{n}$ is generally negative, but it becomes positive for $n \geq 3$ in the presence of ambient westerly winds. In addition, because of large friction losses, $L_{n}$ in layer 2 is smaller than $L_{n}$ in layer 1; it results that the lower cyclone is confined in a close neighborhood of the source; while, in the upper anticyclone slowly decays westwards over the Tropical Atlantic. The westwards shift of the West African high in respect of the source is due to the low frictional losses n layer 1; this shift, accompanied by the lid reaction, is the es\$ential ingredient for the subsidence over the ocean. Fig. 8b shows the shift of $\phi$ in respect of the source as a function of the frictional time. Since the phase shift of the $n$th component is yielded by $\alpha_{n}=\tan ^{-1}\left[\left(c_{n}+U\right) \partial_{x} / \epsilon\right]$, the quadrature, $\alpha=-\frac{\pi}{2}$ in Chen $(2003,2005)$, is obtained for $\epsilon \rightarrow 0$. Fig. $8 \mathrm{c}$ shows that the easterly jet to the south of the DHL is always stronger than the westerly jet to the north of the DHL. This result can be explained by examining the first two equation in (3); in the northern flank of the DHL, $\phi_{n}$ and $u_{n}$ are in-phase because their Term $q_{n+1}(x) D_{n+1}(y)$ has the same sign; while, in the southern flank of the DHL, $\phi_{n}$ and $u_{n}$ are in-phase-opposition because their term $(n+1) q_{n+1}(x) D_{n-1}(y)$ has an opposite sign; finally, the amplifying factor $(n+1)$, makes the southern jet stronger than the northern jet. This asymmetry is due to the latitudinal variation of the Coriolis parameter.

\section{Summer circulation}

In full summer the Saharan heat low shrinks and settles in its most north-westerly position between the Hoggar and the Atlas massifs (Lavaysse et al. 2009); this is also when the Arabian heat low reaches its maximum size and intensity, see Fig. 2a. The dynamics driven by these lows are analyzed here, without duplicating the analysis of the many common features with the spring circulation; namely, lower-level cyclones in-phase with the desert lows, and the upper-level anticyclones to the west of these lows (see Section 4.1). Here we focus on the differences of the shallow circulation due to the higher latitude of the summer DHLs and to a larger size of the AHL in respect of that of the SHL. Because of this size

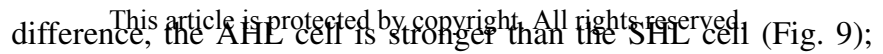

where the AHL cell projects itself over the Libyan desert and the SHL cell projects itself over the Tropical Atlantic. In regions of subsidence, pressure is high and he winds are anticyclonic through the depth of the lower half of the troposphere.

The instability differences between spring and summer seen in Fig. $5 b$ and Fig. 9b are due to the increased value of the Coriolis parameter. In springs, the regions of barotropic instability are larger than those of baroclinic instabilities; in summer, the situation is reversed.

The other differences, such as the westward projection of the upper-level dynamics, are explained in terms of the spectral shifting towards higher order components (larger $n$, see Fig. 4). These components have a smaller westwards $e$-folding distance $L_{n}$ (see Fig. 8a), and a higher critical latitude, $\frac{1}{2} y_{c}^{2}=(2 n+1)$ (or $y_{c}^{2}=2(2 n+1) R_{0}^{2}$, Gill, 1982).

Since reanalysis data show that the winds in the SHL cell are stronger than those in the AHL cell, we search for additional contributors, which can reduce the differences between the circulation seen in Fig. 2 and that seen in Fig. 9. In the remaining part of this section we explore the impact of a third expansion of the Coriolis parameter, the influence by ambient and monsoonal winds and by desert dust warming.

\section{1. $\gamma$-correction}

The $\gamma$-correction is a 3rd order expansion of the Coriolis parameter, $f=\frac{1}{2}\left(y-\gamma y^{3}\right)$, where $\gamma=\frac{1}{6}\left(\frac{R_{0}}{a}\right)^{2}$ and $a$ is the earth radius. The Coriolis parameter, $f$, its form in the equatorial $\beta$-plane and its $\gamma$-correction as a function of latitude are shown in Fig. 10a; and the relative amplitude of the $\gamma$-correction is shown in Fig. 10b; this figure shows that the relative $\gamma$-correction is non negligible in the transition zone between the tropics and the extratropics, where it ranges from $5 \%$ to $15 \%$

Since $\gamma$ is small, its contribution to the dynamics is constructed using a perturbation method, as it is usually done in atmospheric dynamics (Heckley and Gill, 1984; Phlips and Gill, 1987). Then, by posing $(\hat{q}, \hat{r}, \hat{v})=(q, r, v)+\gamma(\tilde{q}, \tilde{r}, \tilde{v})$, where $(q, r, v)$ is the $\beta$-plane solution to Eq. (1) and ( $\tilde{q}, \tilde{r}, \tilde{v})$ is the solution to the following set of equations, which are obtained by equating the 
terms of $\gamma$-order,

$$
\left\{\begin{array}{l}
\left(\epsilon+U \partial_{x}\right) \tilde{q}+\partial_{x} \tilde{q}+\left(\partial_{y}-\frac{1}{2} y\right) \tilde{v}=-\frac{1}{2} y^{3} v \\
\left(\epsilon+U \partial_{x}\right) \tilde{r}-\partial_{x} \tilde{r}+\left(\partial_{y}+\frac{1}{2} y\right) \tilde{v}=\frac{1}{2} y^{3} v \\
2\left(\epsilon+U \partial_{x}\right) \tilde{v}+\left(\partial_{y}+\frac{1}{2} y\right) \tilde{q}+\left(\partial_{y}-\frac{1}{2} y\right) \tilde{r}=y^{3} u
\end{array}\right.
$$

Since $f=\frac{1}{2}\left(y-\gamma y^{3}\right), \gamma$ reduces the Coriolis force. This reduction strengthens of the zonal winds and weakens of the meridional winds, with an increase of pressure at the entrance of the jets and weakening at the exit, which reduces the intensity of the transverse circulations. In zonal jet streaks there two 3

transverse meridional circulations, one at the entrance and the other at exit of the jet (Uccellini and Kocin, 1987). The upper-level esulting circulation is shaped as a qradupole with two cyclones and two anticyclones (Fig. 10c). The anticyclones over the eastern Mediterranean sea and to the west of Gibraltar contribute to the

\section{subsidence in these regions. \\ . Ambient wind influence}

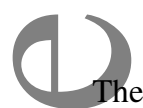

he presence of an easterly ambient wind for $|y|<30^{\circ}$ and of a westerly wind for $|y|>30^{\circ}$ elongates the SHL and the AHL cells, making the zonal winds in the SHL cell stronger than those in the AHL cell, Fig. 11. These ambient winds cause an expansion of the region of instability of the SHL cell and a zonal stretching of the west African high and of the Libyan high.

\subsection{Jet intensification by desert dust warming}

Model and observation results have shown that the solar radiation absorbed by desert dust can play a role in modulating air temperatures, over both land and sea, with important climate impacts (Yoshioka et al. 2007). North Africa is the world's largest source of mineral dust. Dust emission is shaped by the local orography, and its variability ranges from diurnal to decadal timescales (Prospero et al, 2002; Evan et al, 2016). Airborne dust concentration is highest in the $700-500 \mathrm{hPa}$ layer, with a maximum of the solar radiation absorption at $600 \mathrm{hPa}$ (Dunion and Marron, 2008). This absorption causes a lower-level cooling and an upperlevel warmisarticle is protected hy copyright All rights resseryed day $^{-1}$ ] (Carlson and Benjamin, 1980; Lemaître at al, 2010), with observed local maximum as high as $8\left[\mathrm{~K} \mathrm{day}^{-1}\right]$ (Lemaître et al, 2010). The radiative heat balance depends on the underlying surface, and it is influenced by the presence of shallow and/or deep clouds (Carlson and Benjamin, 1980; Bierwirth et al, 2009); and the net heating rate ranges between 1 and $1.5\left[\mathrm{~K} \mathrm{day}^{-1}\right]$ (Carlson and Benjamin, 1980; Evan and Murkhopadhyay, 2010; Lavaysse et al., 2011).

To explore the climatological impact of airborne dust on the dynamics of the shallow circulation, we prescribe a net climatological warming $Q_{D D W}=1\left[\mathrm{~K} \mathrm{day}^{-1}\right]$ over the main desert dust sources (Evan et al, 2016), reducing it to 0.25 [K day $^{-1}$ ] over the ocean (Evan and Murkhopadhyay, 2010). This $Q_{D D W}>0$ depresses the interface between the two layers and drives the upper anticyclone shown in Fig. 12a. The impact of the DDW warming on the circulation driven by the desert lows is shown in Fig. 12b. This additional warming connects the AHL cell to the SHL cell, without substantially changing their structure and shape, but strengthening the SHL cell more than the AHL cell. This behavior is in general agreement with results by Lavaysse et al. (2011), who found that the desert dust radiative forcing increases the SHL thickness, intensifying both AEJ and related AEW activity.

\subsection{Monsoonal influence}

In full summer, North Africa is under the influence of the monsoonal activity (Rodwell and Hoskins, 1996; 2001). Because of the proximity of the west African monsoon (WAM) to the desert lows, WAM has a direct impact on the shallow circulation over this continent. In this work, the analysis is restricted to the oneway influence of WAM on the shallow circulation.

The monsoonal winds and monsoonal subsidence used in this analysis are computed by using a two-layer model with lower frictional layer and an upper almost frictional layer; i.e. the same model already used for the DHLs; but with the following differences, the lid is moved to the top of the troposphere and the source of WAM is placed at one Rossby radius from the equator, with this radius taken equal to $10^{\circ}$. The simulated monsoonal flow is shown in Fig. 13. Because of the low latitude of the source, this flow is dominated by the mixed mode and by the lowest planetary 
mode. These modes drive south-westerly winds in the lower-level and easterly winds in the upper-level, with a vast subsidence region to the south and to west of WAM, and a smaller subsidence region to its north.

Posing that $\left(U_{M}, V_{M}, W_{M}\right)$ are the momentum monsoonal component in the lower half of the troposphere, the contribution of the onshore monsoonal winds is computed by replacing $U \partial_{x}$ with $\left(U_{M} \partial_{x}, V_{M} \partial_{y}\right)$ in Eq. (1), and the contribution of the monsoonal subsidence is computed by replacing the inhomogeneous term in Eq. (2) with $W_{M}$. The simulated circulation is shown in Fig. The monsoonal winds strengthens the lower-level cyclone and the upper-level anticyclone, causing a westward expansion of the AHL and SHL cell. The main contribution of the monsoonal subsidence is the vertical confinement of the shallow circulation.

\section{Summary and conclusions}

he purpose of this work is to propose a minimal theoretical description of the shallow atmospheric circulation over North Africa in terms of large-scale modes (Kelvin, mixed planetarygravity, planetary modes). To this aim, a two-layer MatsunoGill model system is used, in which the dynamics are forced by prescribed buoyancy sources, where mass continuity couples the dynamics in the two layers. The main differences between this model and Gill's model used by Zhang and Krishnamurti (1996) and by Biasutti et al (2009) are: a) the upper layer is almost frictionless in respect of the lower frictional layer (in the cited papers, the frictional losses are uniformly distributed); b) shallow atmospheric circulation is capped by a lid placed at the mid-tropospheric level. c) the contributions by ambient and monsoonal winds, by desert dust warming an by a 3rd-order correction to the Coriolis parameter are also analyzed.

Results show that an upper almost frictionless layer capped by a lid is essential for the formation of the African easterly jet, for the westward displacement of the west African high, for the formation of the Libyan high and for the subsidence over the Tropical Atlantic ocean. These important features are almost absent in simulations done using Gill's classic model, because, since the upper-level anticyclone is specular symmetric in respect of the lower-level cyclone, the subsidence regions are too small and the jets article is protected by copyright. All rights reserved.
Zhang et al (2008) have shown that the shallow circulation over N Africa is not strictly two-dimensional, with a prevailing meridional to zonal seasonal variability. In this work, we show that the subsidence over the Tropical Atlantic to the west of N Africa is driven by westward decaying planetary modes and that the subsidence over the Gulf of Guinea is driven by mixed-planetary modes. The meridional subsidence driven by the mixed mode is strongest when the driving source is at one Rossby radius from the equator; while, the zonal subsidence prevails when the latitude of the source exceeds one Rossby radius.

The spring dynamics are mainly driven by the non-propagating mixed gravity-planetary waves and by the lower order westerly planetary waves, with a weak contribution of the Kelvin waves. In this season, the main driver of the shallow circulation is the desert low located over West Africa, with a small contribution of the desert low located over the Arabia. It results that the main instability region is located to the south-west of the SHL, near the west coast of Africa. This region is displaced further westward by ambient easterly winds.

In summer, the main driver of shallow circulation is the Arabian heat low with a smaller contribution by the Saharan heat low. The model (without additional contributors) produces an AHL cell larger and stronger than the SHL cell. This behavior contradicts with what is seen in Fig. 2, where the SHL winds are stronger than the AHL winds. Candidates, which can contribute to this behavior, are ambient and monsoonal winds and desert dust warming. The monsoonal subsidence is not a main driver of the dynamics, but vertically confines the shallow circulation. Results show that easterly winds and low level convergence of monsoonal winds are able to the strengthen the winds of the SHL cell. An other contributor to these winds is the additional warming due to the presence of airborne dust; while, the $\gamma$-correction almost equally strengthens both cells (SHL and AHL). The presence of these contributors is essential for reproducing the stronger offshore jet seen in Fig. 2a. The instability regions shown in Fig. 11c are consistent with satellite observations, which show that the western coastal region is always rainier than East Africa in both seasons (spring and summer) (Cook, 2015).

In conclusion, the modified two-layer Matsuno-Gill model has shown its ability in reproducing the main features of the 
shallow atmospheric circulation driven by the desert lows, with the monsoonal inland inflow and the airborne desert dust warming playing a non negligible role in the process. These results are in line with more complex models and with observational evidences (see e.g. Thorncroft and Blackburn 1999; Lavaysse et al. 2009; Lavaysse et al. 2011; Spinks et al. 2015; Spinks and Lin, 2015). Hence this simple model is a powerful tool for investigating the behavior of the north African winds under different climatological conditions. Moreover, this model system shows potential implications for the assessment of the remote influences of the North African atmospheric circulation on desert dulst emission and transport (Engelstaedter et al. 2006; Wang et al. 2015), cyclone development in the Tropical Atlantic (Price et al. 2015, Thorncroft and Hodges 2001), and monsoonal precipitation distribution in the Sahel (Lavaysse et al. 2010b; Lavaysse et al. 2015).

The limitations due the linearity of the model-system can be partially overcome by introducing a nonlinear correction (see Gill and Phlips, 1986); however, nonlinearities due to presence of mountains of finite altitude are unresolved by this type of correction (Rodwell and Hoskins, 2001). In addition, feedback mechanisms between heating and low level dynamics in the onset phase of the west African monsoon cannot be resolved by impulsive forcing has done in Heckley and Gill (1984), because of their inherent nonlinear nature. In addition, North Africa and the Mediterranean region are under the influence of the south Asian monsoon (Rodwell and Hoskins, 1996; 2001), and this ontribution is absent in this work. Summarizing, the monsoonal influence on the desert lows present in this work only refers to the summer shallow circulation over North Africa, when WAM is in its mature stage. Therefore, the results shown in this paper can be expanded by doing further work.

\section{Acknowledgements}

This work benefits of constructive comments by both reviewers. Data are extracted from the ERA-Interim dataset (http://apps.ecmwf.int/datasets/), for the period 1979-2015. M. Gaetani has been supported by the LABEX project funded by the Agence Nationale de la Recherche (French National Research Agency, gris article $A$ S Rrotgcted the support of the Italian CNR Short Term Mobility (STM) Program. M. Baldi and G. Dalu are deeply grateful to C. Flamant for his kind hospitality and useful discussions during their visit at LATMOS-IPSL in Paris, France.

\section{A. Appendix}

\section{A.1. ODEs in terms of parabolic cylindrical functions}

The expansion of the source in terms of parabolic cylindrical functions, $Q(x, y)=X(x) \sum_{n=0}^{N} Q_{n} D_{n}(y)$, where $X(x)=$ $\sin \left[k\left(x-x_{0}\right)\right]$, is used for reducing the PDE in Eq. (1) in a set of ODE,

$$
\left\{\begin{array}{l}
{\left[\epsilon+U \mathcal{D}_{x}\right] q_{n+1}+\mathcal{D}_{x} q_{n+1}-v_{n}=-Q_{n+1} X(x)} \\
{\left[\epsilon+U \mathcal{D}_{x}\right] r_{n-1}-\mathcal{D}_{x} r_{n-1}+n v_{n}=-Q_{n-1} X(x)} \\
2\left(\epsilon+U \mathcal{D}_{x}\right) v_{n}+(n+1) q_{n+1}-r_{n-1}=0
\end{array}\right.
$$

where $(q, r, v)=\left[q_{n}(x), r_{n}(x), v_{n}(x)\right] \sum_{n=0}^{N} D_{n}(y)$, In the above equations, the following recursion formula have been used, $\left(\mathcal{D}_{y}+\frac{1}{2} y\right) D_{n}=n D_{n-1}$ and $\left(\mathcal{D}_{y}-\frac{1}{2} y\right) D_{n}=-D_{n+1}$. Since $\mathrm{O}(U, \epsilon)<1$ (finite but smaller than one) and $\mathrm{O}\left(U^{2}, \epsilon^{2}\right)<<1$, we first construct the leading order solution by neglecting terms of $\mathrm{O}(U, \epsilon)$, then this solution is corrected up to $\mathrm{O}(U, \epsilon)$; while $\mathrm{O}\left(U^{2}, \epsilon^{2}\right)$ terms and higher order terms are neglected.

\section{A.2. Kelvin mode excited by $Q=Q_{0} X(x) D_{0}(y)$}

For $q \neq 0$ and $(v, r)=0$, the 1 st equation in (5) yields,

$$
\left[\epsilon+(1+U) \mathcal{D}_{x}\right] q_{0}(x)=-X(x) Q_{0}
$$

Kelvin modes are easterly waves which vanish to the west of the source; posing $q_{0}=q_{0}^{F}+q_{0}^{f}$, where $q_{0}^{F}(x)$ and $q_{0}^{f}(x)$ are the respective forced and free mode, the solution to the above equation 
is yielded by

$$
\left\{\begin{array}{l}
q_{0}^{F}=A[\cos (k x)-\alpha \sin (k x)] \text { for } 0 \leq k x \leq \pi \\
q_{0}^{f}=B \exp (-\alpha k x) \text { and } \alpha=\epsilon[k(1+U)]^{-1} \\
\text { with } A=k Q_{0}\left[\left(1+\alpha^{2}\right)(1+U)\right]^{-1}
\end{array}\right.
$$

(1).

flow continuity, a free mode of amplitude $B=-A$ is added for $k x \geq 0$, and a free mode of amplitude $B=-A \exp (\alpha \pi)$ is added beyond the for $k x \geq \pi$.

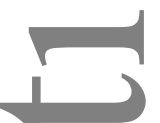

1

A.3. Mixed mode excited by $Q=Q_{1} X(x) D_{1}(y)$ for $q, v) \neq 0$ and $r=0$

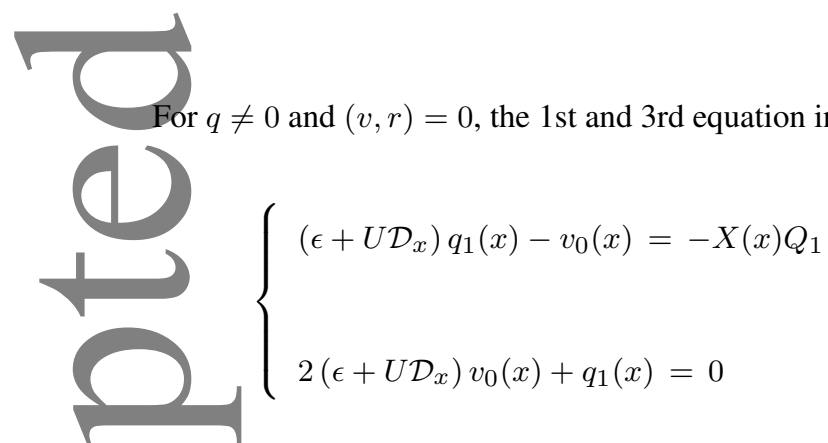

The leading order forced solution and its $\mathrm{O}(U, \epsilon)$ correction are respectively yielded by

$$
\left\{\begin{array}{l}
v_{0}^{F}+\Delta v_{0}^{F}=Q_{1} X(x)+\left(\epsilon+U \mathcal{D}_{x}\right) \Delta q_{1}^{F} \\
\Delta q_{1}^{F}=-2 Q_{1}[k U \cos (k x)+\epsilon \sin (k x)]
\end{array}\right.
$$

The decaying rate of the free modes are yielded by the roots of the dispersion relation constructed by reducing Eq. (7) to one equation for $v_{0} \propto \exp (\alpha x), U(1+U) \alpha^{2}+\epsilon(1+2 U) \alpha+$ $\left(\frac{1}{2}+\epsilon^{2}\right)=0$. For $U<0$, the two roots are real, and the source is bounded by a western inertial layer, $\Delta v_{0}^{f} \propto \Delta v_{0}^{F} \exp \left(\alpha_{1} x\right)$, and by an eastern inertial layer, $\Delta v_{0}^{f} \propto \Delta v_{0}^{F} \exp \left(\alpha_{2} x\right)$, where $\alpha_{1}>0$ and $\alpha_{2}<0$. For $U>0$, the two roots are complex, $\alpha_{12}=$ $\alpha_{r} \pm i \alpha_{i}$ with $\alpha_{r}<0$, and the source is bounded by an eastern oscillatory waticle is inrotected by copvright $\Delta v_{0}$ All rights resserved.

\section{A.4. Planetary mode excited by $Q=X(x) Q_{n} D_{n}(y)$ for}

$(q, r, v) \neq 0$

Neglecting terms of $\mathrm{O}(U, \epsilon)$, but keeping $2(n+1) \mathrm{O}(U, \epsilon)$ terms, the long planetary waves are yielded by

$$
\left\{\begin{array}{l}
\left(c_{n}+U\right) \partial_{x} q_{n+1}^{F}+\epsilon q_{n+1}^{F} \\
=c_{n}\left[Q_{n-1}+n Q_{n+1}\right]\left[1+2 \mathcal{D}_{x}\left(\epsilon+\mathcal{D}_{x} U\right)\right] X(x) \\
v_{n}^{F}=2(n+1)\left[\epsilon+U \partial_{x}\right] q_{n+1}^{F} \\
\quad+\left[Q_{n-1}+(n+1) Q_{n+1}\right] X(x) \\
\\
r_{n-1}^{F}=(n+1) q_{n+1}^{F}
\end{array}\right.
$$

where $L_{n}=-\epsilon^{-1}\left(c_{n}+U\right)$ is the $e-$ folding distance of the free modes and $c_{n}=-\left(2 n+1+2 k^{2}\right)^{-1}$ is their phase speed; these modes decay westerly for $\left(c_{n}+U\right)<0$, and easterly for for $\left(c_{n}+\right.$ $U)>0$. There is also an additional a train of rapidly decaying waves yielded by

$$
\left\{\begin{array}{l}
\left(c_{n}+U\right) \partial_{x} \Delta q_{n+1}^{F}+\epsilon \Delta q_{n+1}^{F} \\
\quad=c_{n}\left[Q_{n-1}+(n+1) Q_{n+1}\right]\left[2 k^{2} U \sin (k x)-2 \epsilon k \cos (k x)\right] \\
\Delta v_{n}^{F}=\partial_{x} \Delta q_{n+1}^{F}, \quad \Delta r_{n-1}^{F}=n \Delta q_{n+1}^{F}
\end{array}\right.
$$

The decaying rate of these free modes are yielded by the roots of the dispersion relation constructed by reducing Eq. (5) to one equation for $q_{n+1} \exp (\alpha x), 2 U \alpha^{3}+2 \epsilon \alpha^{2}+[1-(2 n+1) U] \alpha-$ $(2 n+1) \epsilon=0$. Then, neglecting the root related to the $q_{n}^{F}$, the other two roots are related to $\Delta q_{n}^{F}$. As in the mixed modes, for $U<0$ the source is bounded by a western and an eastern inertial layer; while for $U>0$, the source is bounded by an eastern oscillatory wave.

\section{References}

Biasutti M, Sobel AH, Camargo SJ. 2009. The role of the Sahara low in summertime Sahel rainfall variability and change in the CMIP3 models. J. Clim., 22: 5755-5771.

Bierwith S, M Wendish, A Ehrlich, Heese B, Tesche M, Altahuasen D, A Schadlitz, D Miller, S Otto, T Trautmann, Dinter T, W von hoyningenHuene, R Kahn. 2009. Spectral surface albedo over Marocco and its impact on radiative forcing of Saharan dust. Tellus, 61B: 352-369. 
Carlson TN and SG Benjamin. 1980. Radiative heating rates for Saharan dust.

J. Atmos. Sci., 37: 193-213.

Chen TC. 2003. Maintenance of summer monsoon circulation: a planetaryscale prospective. J. Clim., 16: 2022-2036.

Chen TC. 2005. Maintenance of the midtropospheric North African summer circulation: Saharan high and African easterly jet. J. Clim., 18: 2843-2962.

Chauvin F, Roehrig R, Lafore JP. 2010. Intraseasonal variability of the saharan heat low and its link with midlatitudes. J. Clim., 23: 25442561,

\section{doi:10.1175/2010JCLI3093.1.}

Cook KH. 1999. Generation of the African easterly jet and its role in determining West African precipitation. J. Clim., 12(5): pp.1165-1184.

Cook KH. 2015. Role of inertial instability in the West African monsoon jump. J. Geophys. Res. Atmos., 120(8): pp.3085-3102.

Dunion JP, Marron JM. 2008. A reexamination of the Jordan mean tropical $r$ Dunion sounding baxed on awareness of the Saharan air layer: results from 2002. J. Clim., 21: 5242-5253.

Engelstaedter S, Tegen I, Washington R. 2006. North African dust emissions and transport. Earth-Science Rev., 79(1-2): 73100, doi:10.1016/j.earscirev.2006.06.004.

Evan AT, Murkhopadhyay S. 2010. African dust over northern Tropical Atlantic: 1955-2008. J. Appl. Meteor. Climatol, 49: 2213-2229.

Evan AT, Flamant C, Lavaysse C, Kocha C, Saci A. 2015. Water VaporForced Greenhouse Warming over the Sahara Desert and the Recent Recovery from the Sahelian Drought. J. Clim., 28: 108123, doi:10.1175/JCLI-D-1400039.1

Evan AT, Flamant C, Lavaysse C, M Gaetani, and F Guichard. 2016. The past, present and future of African dust. Nature, 531: 493497, doi:10.1038/nature17149.

M, Fontaine B, Roucou P, Baldi M. 2010. Influence of the Mediterranean Sea on the West African monsoon: Intraseasonal variability in numerical simulations. J. Geophys. Res. Atmos., 115: D24115, doi:10.1029/2010JD014436.

Gill AE. 1980. Some simple solutions for heat-induced tropical circulation. $Q$. J. R. Meteorol. Soc., 106: 447-462.

ill AE, Phlips PJ. 1986. Nonlinear effects of heat-induced circulation of the tropical atmosphere. Q. J. R. Meteorol. Soc., 112: 69-91.

Gu G, Adler RF, Huffman GJ, Curtis S. 2004. African easterly waves and their association with precipitation. J. Geophys. Res. Atmos., 109: D04101, doi:10.1029/2003JD003967.

Heckley WA, Gill AE. 1984. Some simple analytical solutions to the problem of forced equatorial long waves. Q. J. R. Meteorol. Soc., 110: 203-217.

Lamaître C, C Flamant, J-C Raul, P Chazet, P Formenti, and J Pelon. 2010.Radiative heating rate profiles associated with a springtime Bodele and Sudan dust transport over West Africa. J. Atmos. Chem. Phys., 10: 8131-8150.
Landsea CW, Gray WM. 1992. The strong association between western Sahelian monsoon rainfall and intense Atlantic Hurricanes. J. Clim., 5: 435453.

Lavaysse C, Flamant C, Janicot S, Parker DJ, Lafore JP, Sultan B, Pelon J. 2009. Seasonal evolution of the West African heat low: A climatological perspective. Clim. Dyn. , 33: 313330, doi:10.1007/s00382-009-0553-4.

Lavaysse C, Flamant C, Janicot S, Knippertz P. 2010a. Links between African easterly waves, midlatitude circulation and intraseasonal pulsations of the West African heat low. Q. J. R. Meteorol. Soc., 136: 141158, doi:10.1002/qj.555.

Lavaysse C, Flamant C, Janicot S. 2010b. Regional-scale convection patterns during strong and weak phases of the Saharan heat low. Atmos. Sci. Lett., 11: 255264, doi:10.1002/asl.284.

Lavaysse C, Chaboureau JP, Flamant C. 2011. Dust impact on the West African heat low in summertime. Q. J. R. Meteorol. Soc., 137: 12271240, doi:10.1002/qj.844.

Lavaysse C, Flamant C, Evan A, Janicot S, Gaetani M. 2015. Recent climatological trend of the Saharan heat low and its impact on the West African climate. Clim. Dyn., doi:10.1007/s00382-015-2847-z.

Matsuno T. 1966. Quasi-geostrophic motions in the equatorial area. J. Meteorol. Soc. Jpn., 44, 2543.

Neelin JD. 1989. On the interpretation of the Gill model. J. Atmos. Sci., 46: 2466-2468.

Peyrillé P, Lafore JP. 2007. An Idealized Two-Dimensional Framework to Study the West African Monsoon. Part II: Large-Scale Advection and the Diurnal Cycle. J. Atmos. Sci., 64: 27832803, doi:10.1175/JAS4052.1.

Phlips PJ, Gill AE. 1987. An analytic model of the heat-induced tropical circulation in the presence of a mean wind. Q. J. R. Meteorol. Soc., 113: 213-236.

Price C, Reicher N, Yair Y. 2015. Do West African thunderstorms predict the intensity of Atlantic hurricanes? Geophys. Res. Lett., 42: 24572463, doi:10.1002/2014GL062932.

Prospero JM, P Ginoux, O Torres, Se Nicholson. 2002. Environmental characterization of gloabal sources of atmospheric soil dust derived from the NIMBUS7 TOMS absorbing aerosol products. Rev. Geophys., 40(1), 1002.

Rodwell MJ, Hoskins BJ. 1996. Monsoons and the dynamics of deserts. Q. J. R. Meteorol. Soc., 122: 1385-1404.

Rodwell MJ, Hoskins BJ. 2001. Subtropical anticyclones and summer monsoons. J. Clim., 14: 3192-3211.

Schubert WH, Ciesielski PE, Stevens DE, Kuo HC. 1991. Potential vorticity modelling of the ITCZ and the Hadley circulation. J. Atmos. Sci., 37: 14931500 .

Skinner CB, Diffenbaugh NS. 2013. The contribution of African easterly waves to monsoon precipitation in the CMIP3 ensemble. J. Geophys. Res. Atmos., 118: 35903609, doi:10.1002/jgrd.50363.

This article is protected by copyright. All rights reserved. 
Spinks J, Lin YL, Mekonnen A. 2015. Effects of the subtropical anticyclones over North Africa and Arabian Peninsula on the African easterly jet. Int. J. Climatol., 35: 733745. doi:10.1002/joc.4017.

Spinks J, Lin YL. 2015. Variability of the subtropical highs, African easterly jet and easterly wave intensities over North Africa and Arabian Peninsula in late summer. Int. J. Climatol., 35: 35403555. doi:10.1002/joc.4226.

Stevens B, Duan J, McWilliams JC, Mnnich M, Neelin JD. 2002. Entrainment, Rayleigh friction, and boundary layer winds over the tropical Pacific. $J$. Clim., 15: 30-44. Thorncroft CD, Blackburn M. 1999. Maintenance of the African easterly jet. Q. J. R. Meteorol. Soc., 125 : 763786, doi:10.1002/qj.49712555502.

Thorncroft CD, Hodges K. 2001. African Easterly Wave Variability and Its Relationship to Atlantic Tropical Cyclone Activity. J. Clim., 14: 11661179 Thbrncroft CD, Hoskins BJ. 1994a. An idealized study of African easterly rov Javes. Part I, a linear view. Q. J. R. Meteorol. Soc., 120: 953-982.

Thorncroft CD, Hoskins BJ. 1994b. An idealized study of African easterly waves. Part II, a nonlinear view. Q. J. R. Meteorol. Soc., 120: 1589-1614. Uccellini LW, Kocin J. 1987. Interaction of jet circulations during heavy snow events along the East Coast of the United States. Weather and Forecasting, 2, 289-308.

Vallis GK. 2010. Atmospheric and Oceanic Fluid Dynamics. Cambridge University Press, 745 pp.

Vizy EK, Cook KH. 2009. A mechanism for African monsoon breaks: Mediterranean cold air surges. J. Geophys. Res. Atmos., 114: 119, doi:10.1029/2008JD010654.

Wang W, Evan AT, Flamant C, Lavaysse C. 2015. On the decadal scale correlation between African dust and Sahel rainfall: The role of Saharan

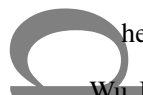
heat lowforced winds. Science advances, 1(9), p.e1500646.

Wu ML, Reale O, Schubert SD, Suarez MJ, Koster RD, Pegion PJ. 2009. African easterly jet: Structure and maintenance. J. Climate, 22, 44594480

ML, Reale O, Schubert SD, Suarez MJ, Thorncroft CD. 2012. African Easterly Jet: Barotropic Instability, Waves, and Cyclogenesis. J. Clim., 25: 14891510, doi: 10.1175/2011JCLI4241.1.

Yoshioka M, Mahowald NM, Conley AJ, Collins WD, Fillmore DW, Zender CS, Coleman DB. 2007. Impact of desert dust radiative forcing on Sahel precipitation: Relative importance of dust compared to sea surface temperature variations, vegetation changes, and greenhouse gas warming. J. Clim., 20: 1445-67.

Zhang C and TN Krishanamurti. 1996. A generalization of Gill's heat-induced tropical circulation. J. Atmos. Sci., 53: 1045-52.

Zhang C, DS Nolan, CD Thorncroft, and H Nguyen. 2008. Shallow atmospheric circulations in the tropical atmoshere. J. Clim., 21: 3453-70. 

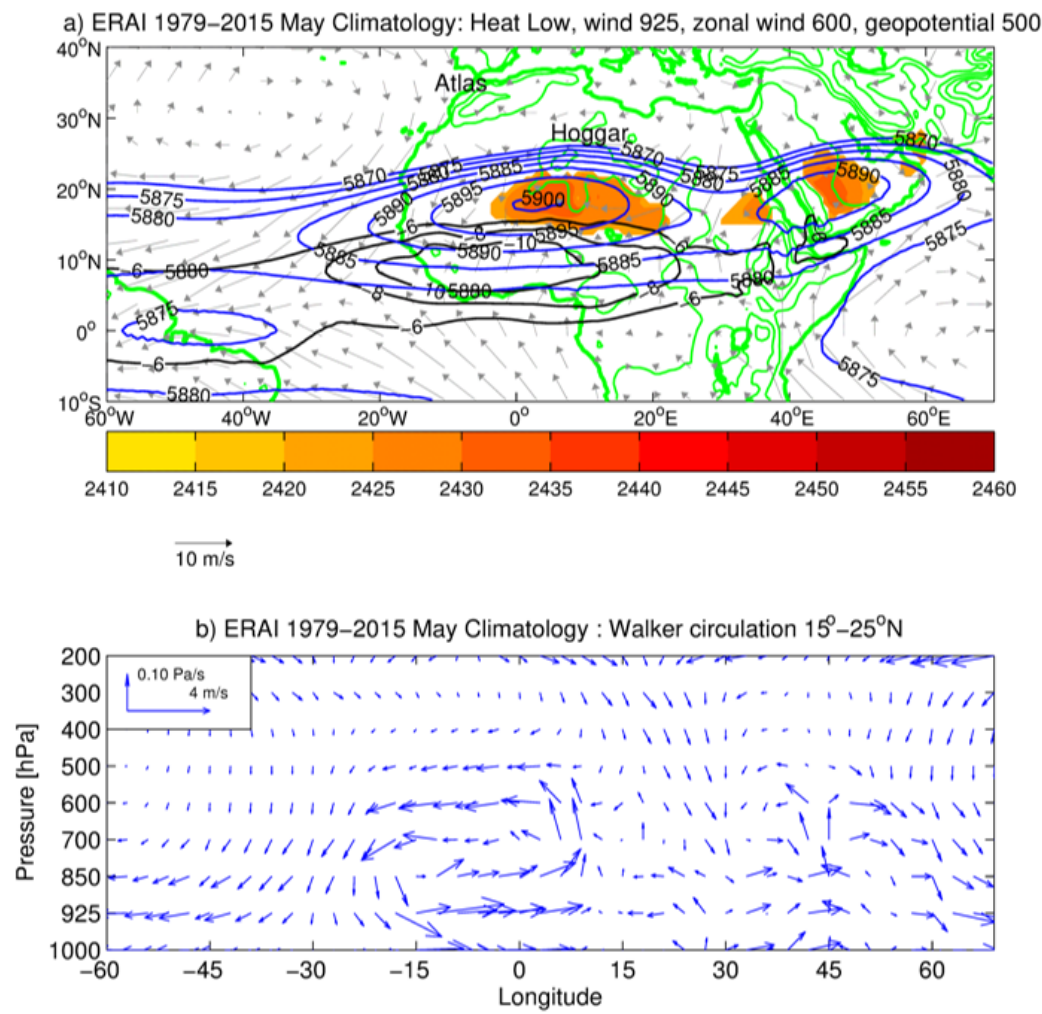

Figure 1: Climatology of the shallow atmospheric over North Africa in May. Upper panel wind vector at $925 \mathrm{hPa}, 700-925$ thickness $[\mathrm{m}]$ at $850[\mathrm{hPa}]$ (red tones), zonal wind [m/s] at $600 \mathrm{hPa}$ (black solid line), geopotential [m] at $500 \mathrm{hPa}$ (blue solid line); over land orography in thin green lines $\Delta \mathrm{h}=600[\mathrm{~m}]$. Lower panel, meridional circulation represented trough the vertical velocity and the divergent zonal wind component.
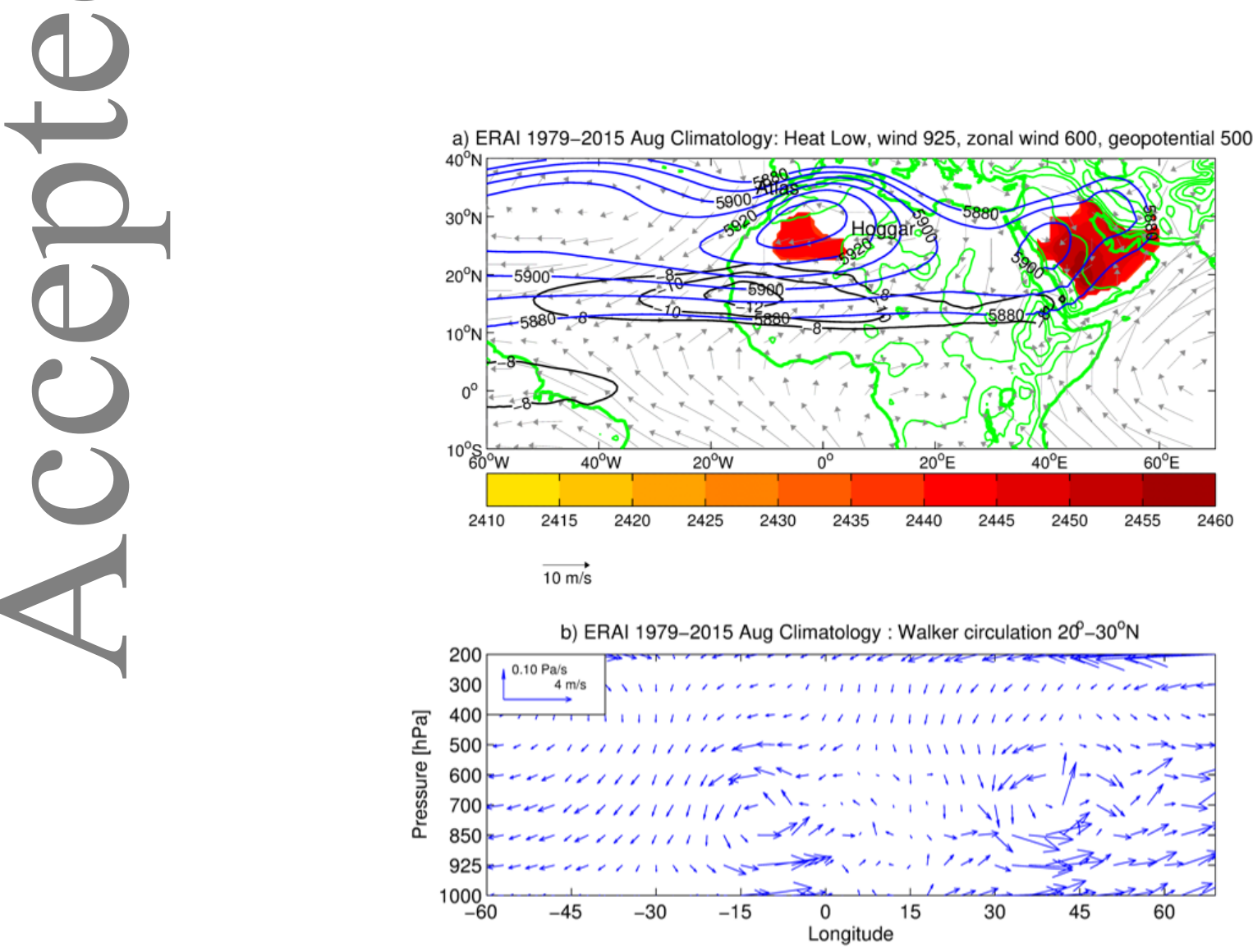

Figure 2: Same as Fig. 1, in August.

This article is protected by copyright. All rights reserved. 


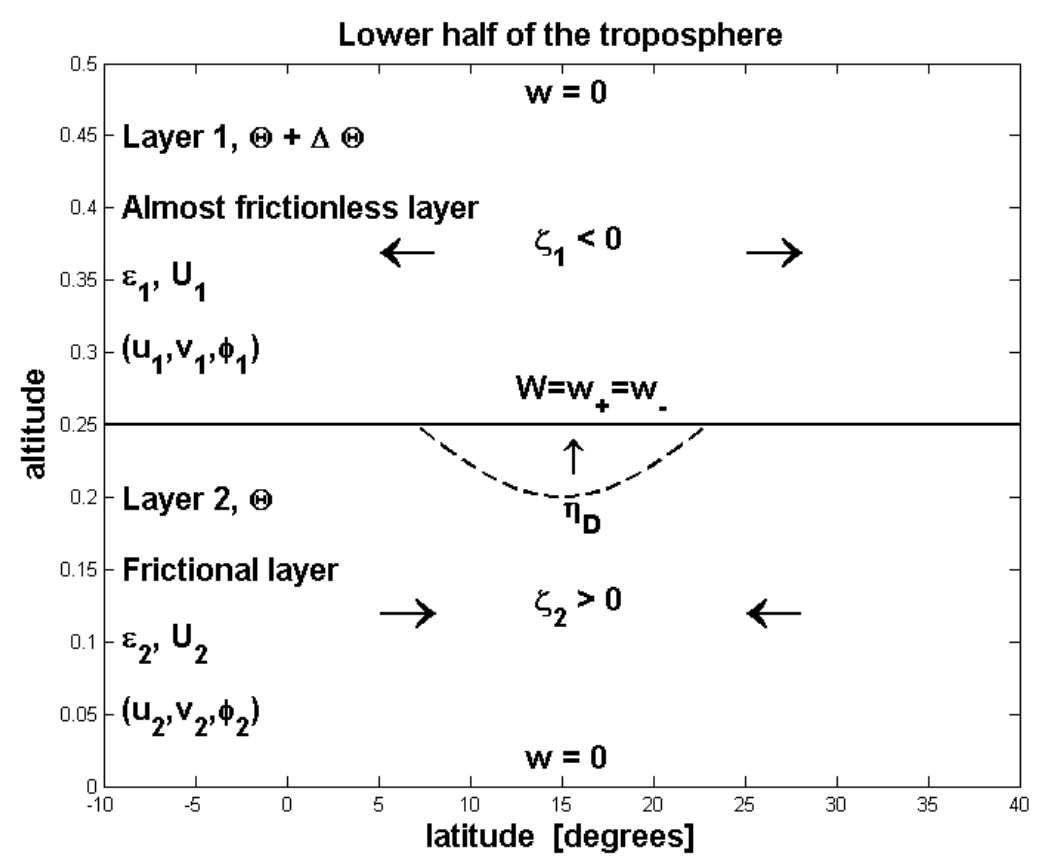

Figure 3: Latitudinal vertical cross section of the two-layer model. $(u, v, \zeta, \phi, \epsilon)$ wind components, relative vorticity, pressure and friction coefficient, respectively. $(U, \Theta)$ ambient wind and potential temperature, respectively. $\left(W, \eta_{D}\right)$ vertical velocity and interface displacement, respectively. 
a) Desert heat low spectrum
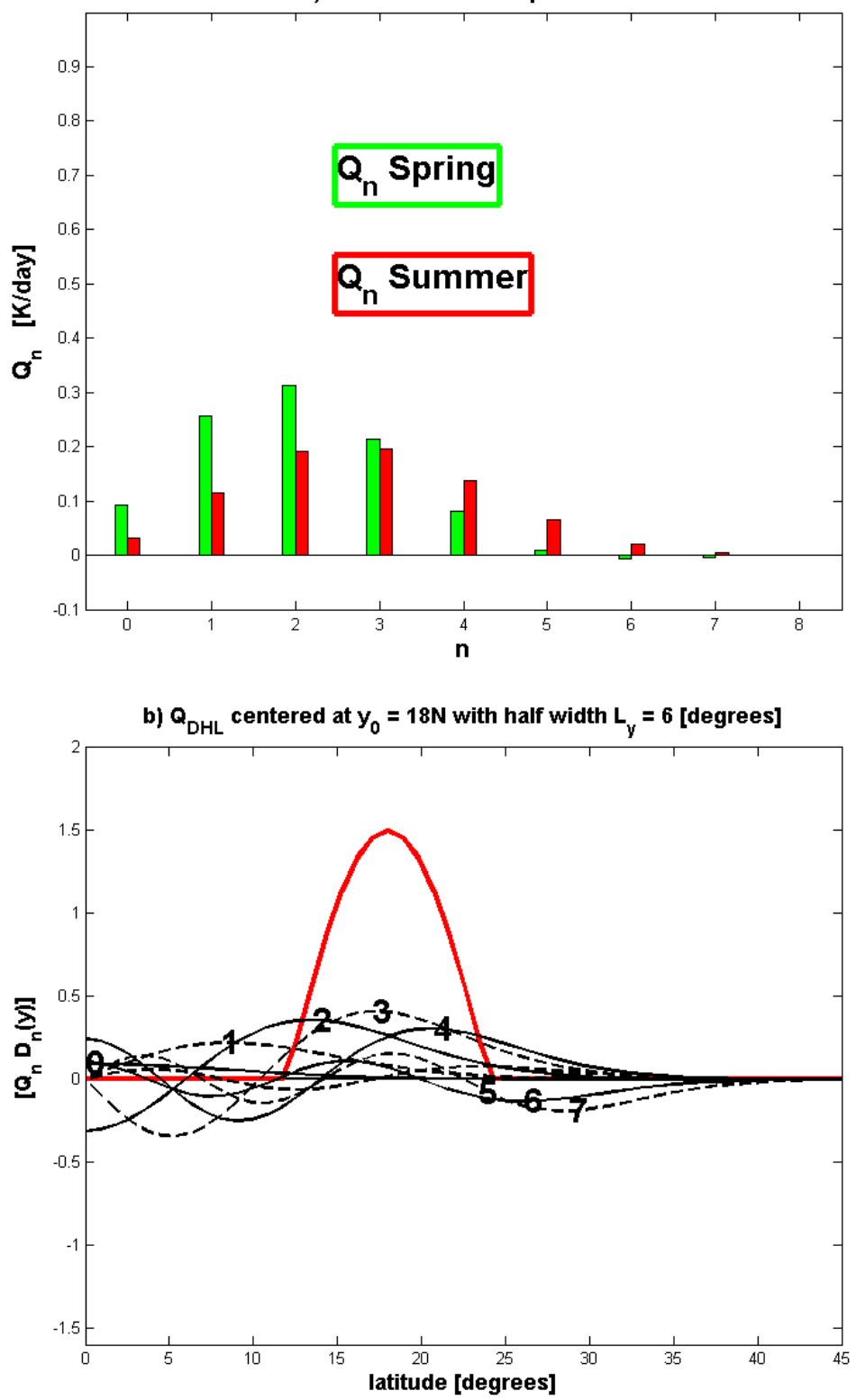

c) $Q_{D H L}$ at $y_{0}=24 \mathrm{~N}$ with half width $L_{y}=7$ [degrees]

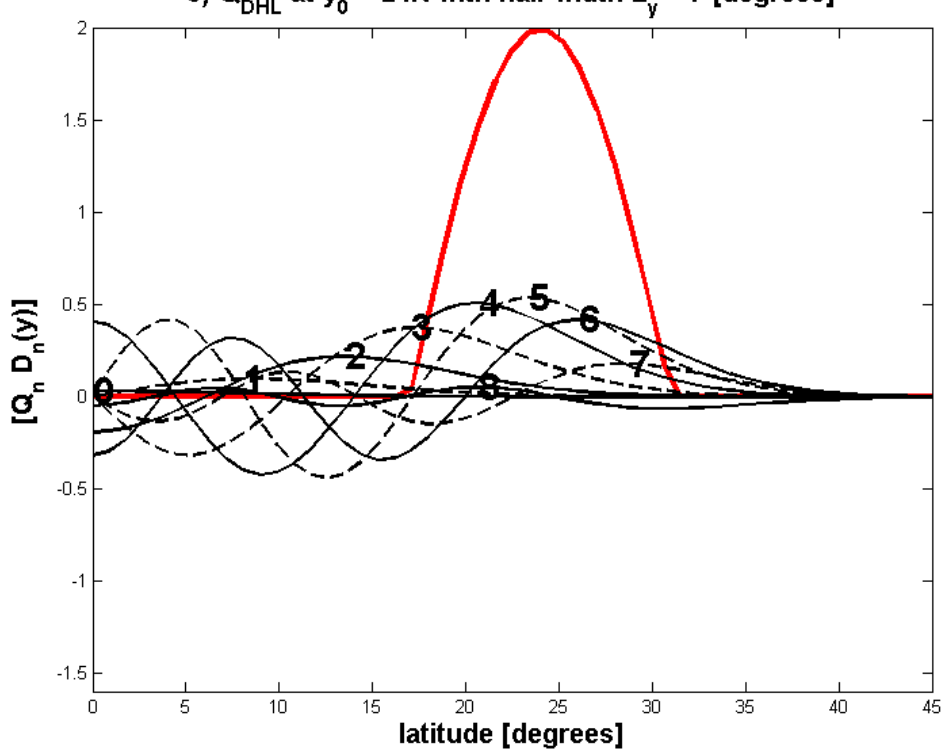

Figure 4: a) Source spectrum, spring (green) and summer (red) [K/day]; b) Spring source (red) and its meridional components, even (black solid) and odd (black dash). c) Same as b), but summer source.

This article is protected by copyright. All rights reserved. 
a) Barotropic mode driven by the lid reaction, $\phi_{\text {Lid }}$

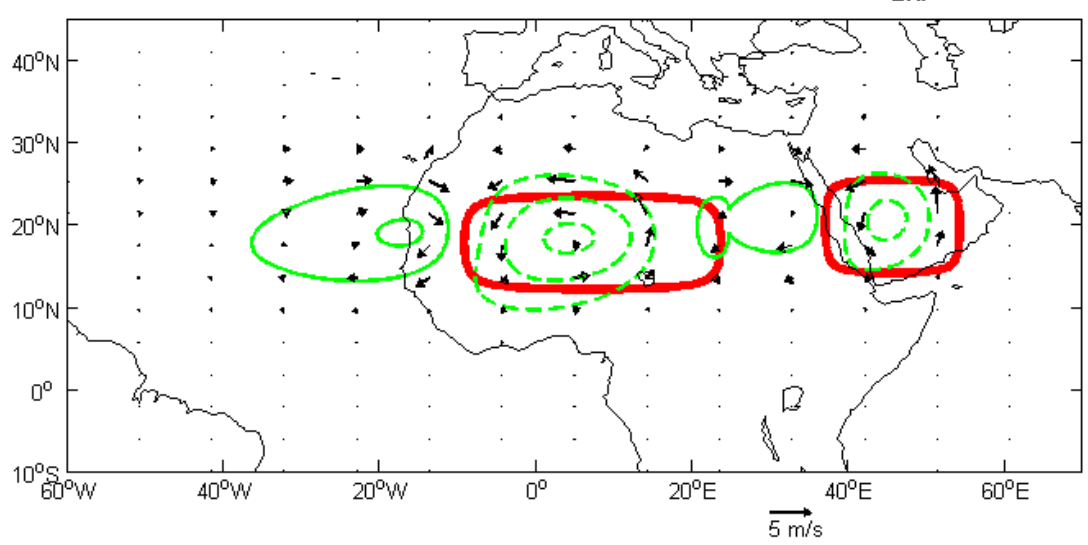

b) Upper-level winds \& $\phi_{1}$

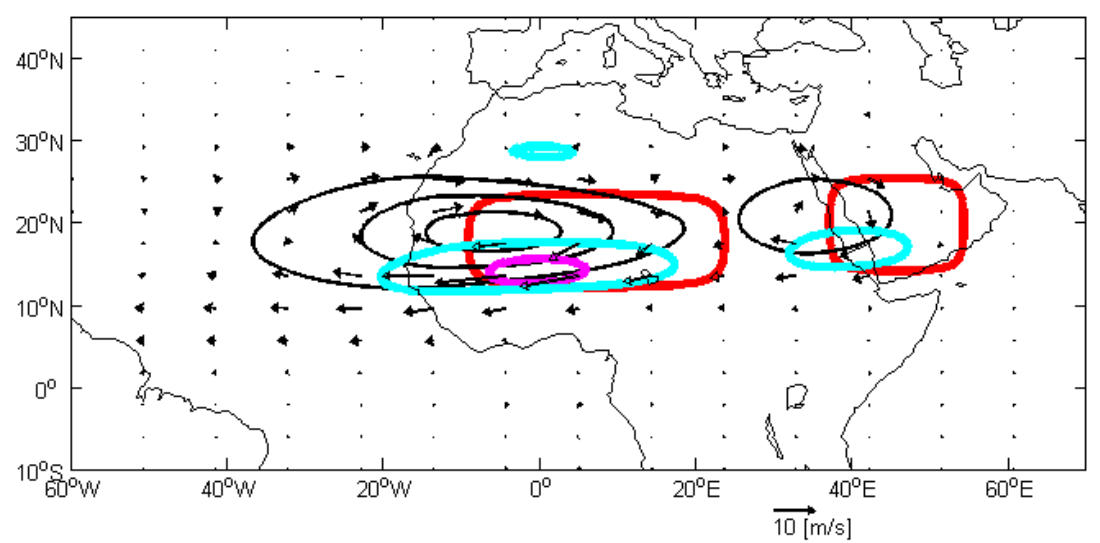

c) Vertical velocity at the interface, $W$

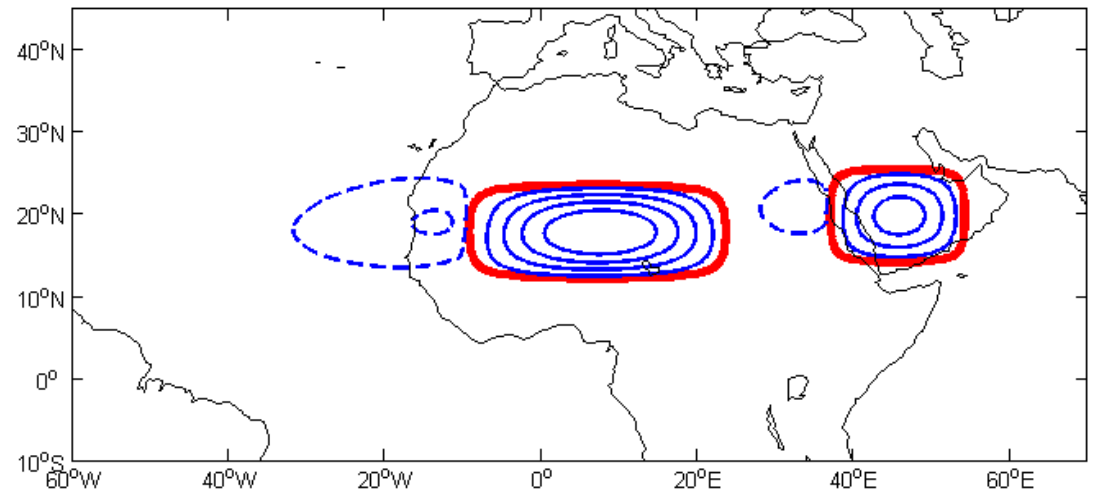

d) Lower-level winds $\& \phi_{2}$



Figure 5: Spring circulation where $U=0$ and $\epsilon_{1}=0.2 \epsilon_{2}, Q_{S H L}$ and $Q_{A H L} 0.1$ red contour. a) Lid reaction, $\Delta \phi_{L i d}=5$ [m] green. b) Upper-level winds, $\Delta \phi_{1}=10$ [m] black; regions of barotropic and baroclinic instabilities encircled by cyan and magenta lines, respectively. c) Vertical velocity at the interface, upwelling $\Delta W=5[\mathrm{~mm} / \mathrm{s}]$, downwelling $\Delta W=2[\mathrm{~mm} / \mathrm{s}]$, d) Lower-level winds, $\Delta \phi_{2}=5$. [m] artickek 1 . protected by copyright. All rights reserved. 
a) Upper-level winds \& $\phi_{1}$

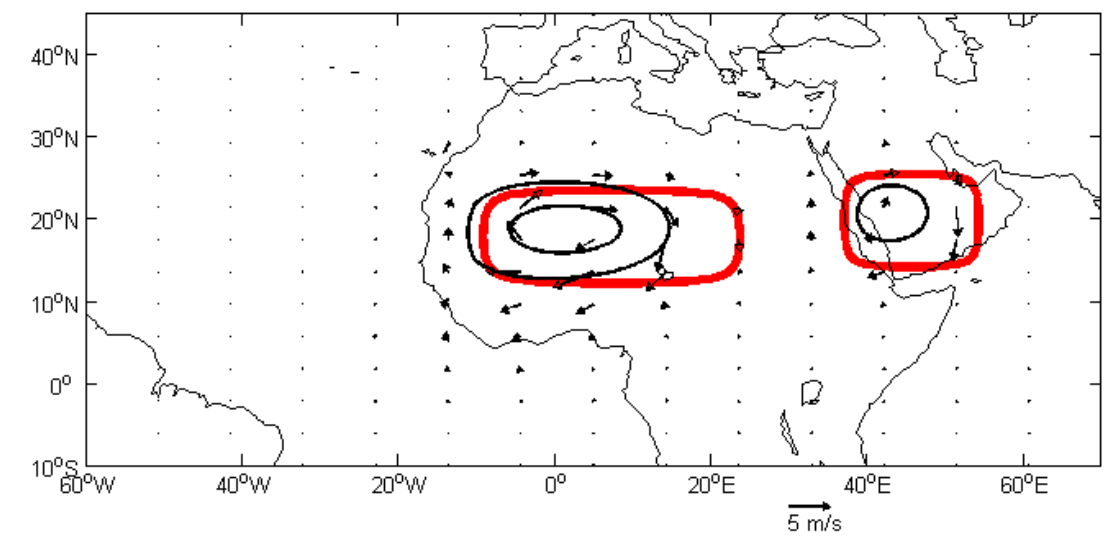

b) Vertical velocity at the interface, $W$



c) Lower-level winds $\& \phi_{2}$

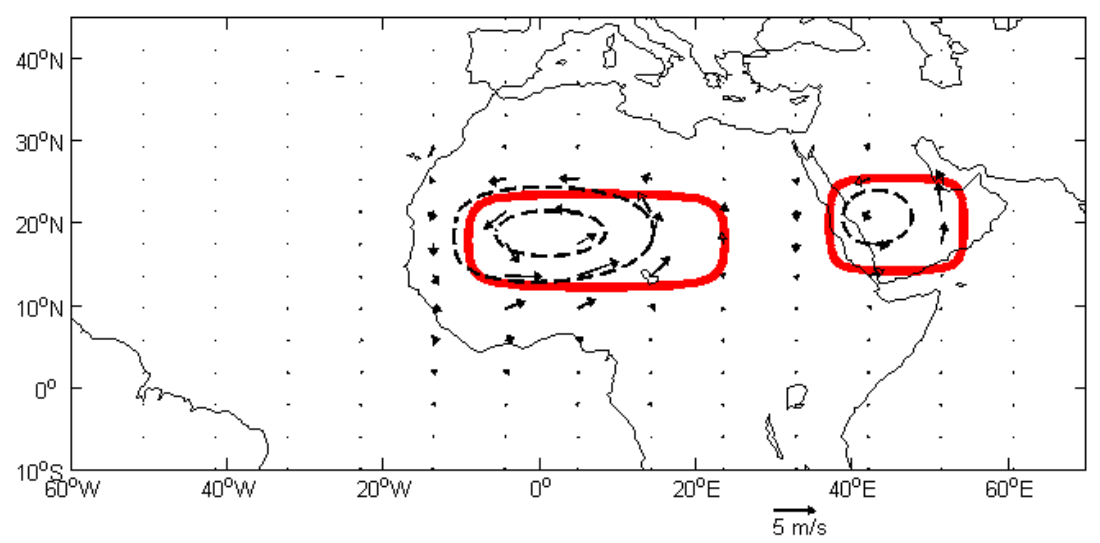

Figure 6: Same as Fig. 5, but when $\epsilon_{1}=\epsilon_{2}$ and $\Delta \phi_{1}=\Delta \phi_{2}=5$ [m] for both layers.

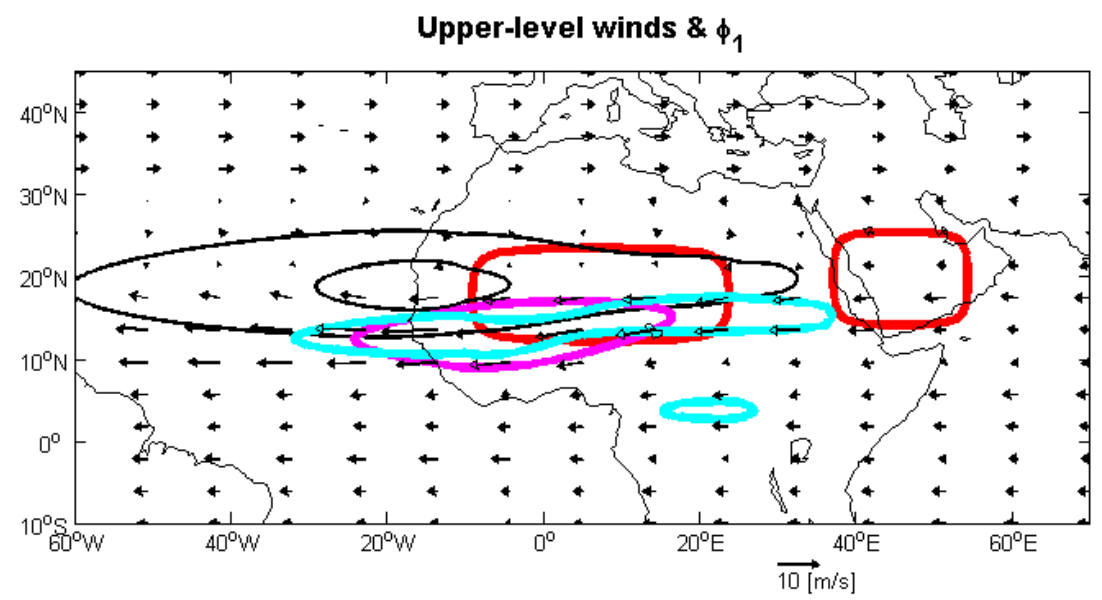


a) Planetary wave e-folding distance from the source $\left(L_{n}>0\right.$, easterly; $L_{n}<0$, westerly)
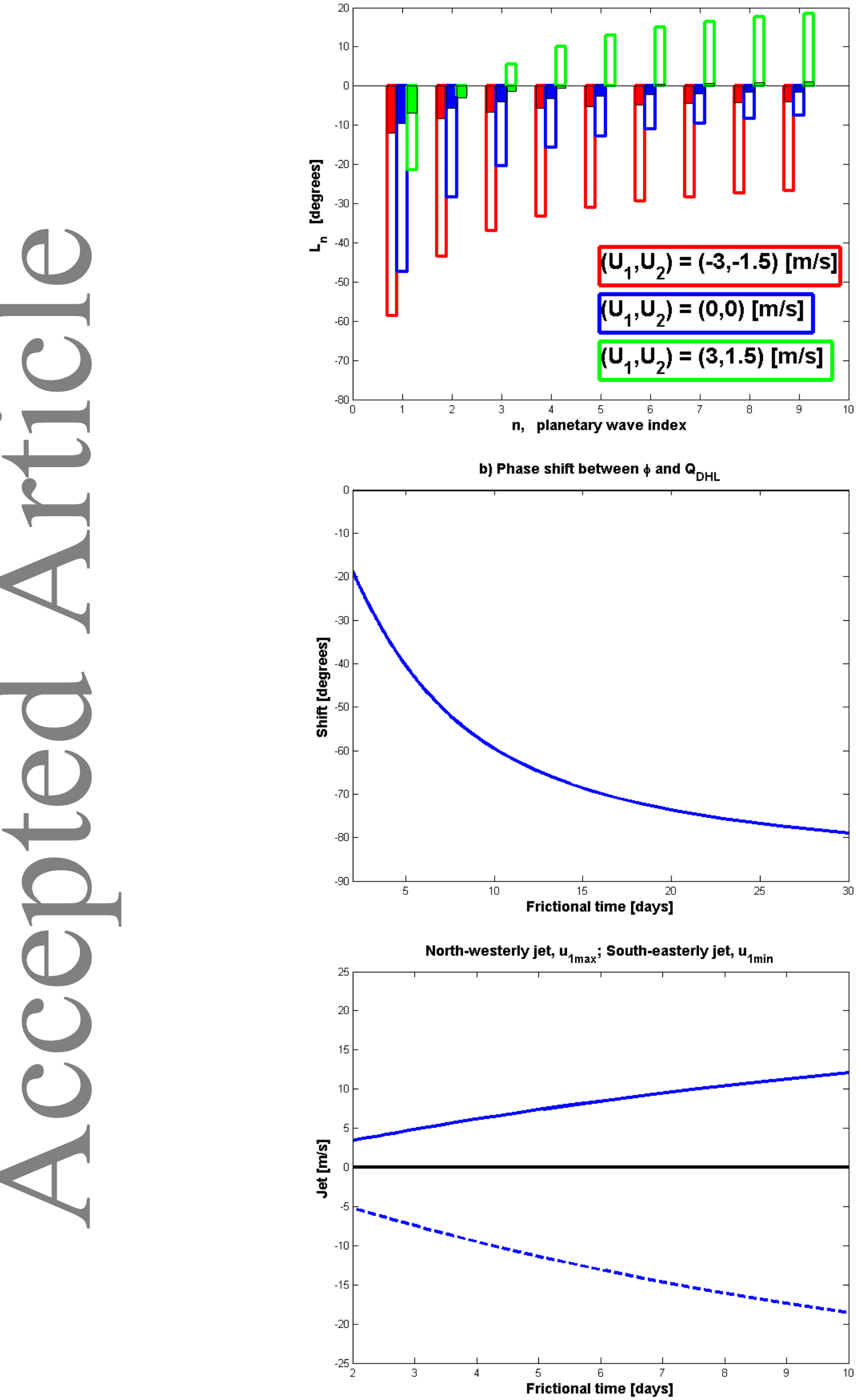

Figure 8: a) e-folding distance from the source, $L_{n}$, of the $n$th planetary mode (edged layer 1 and solid layer 2). b) Phase shift of the west African high, $\phi_{1}$, in respect of the source as a function of the frictional time (solid blue). c) Intensity of westerly jet to the north




a) Barotropic mode driven by the lid reaction, $\phi_{\text {Lid }}$

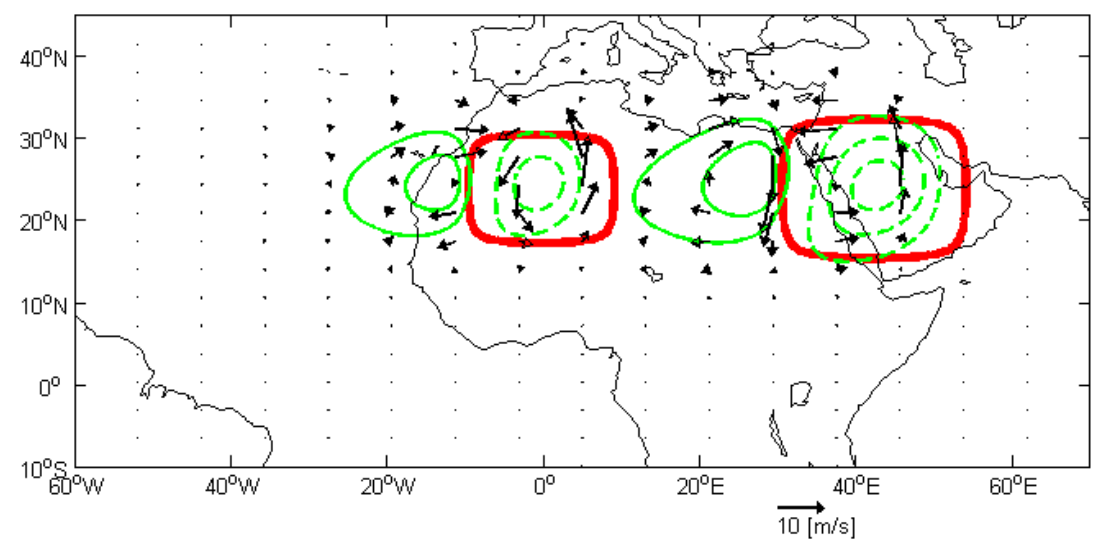

b) Upper-level winds \& $\phi_{1}$



c) Vertical velocity at the interface, $w$

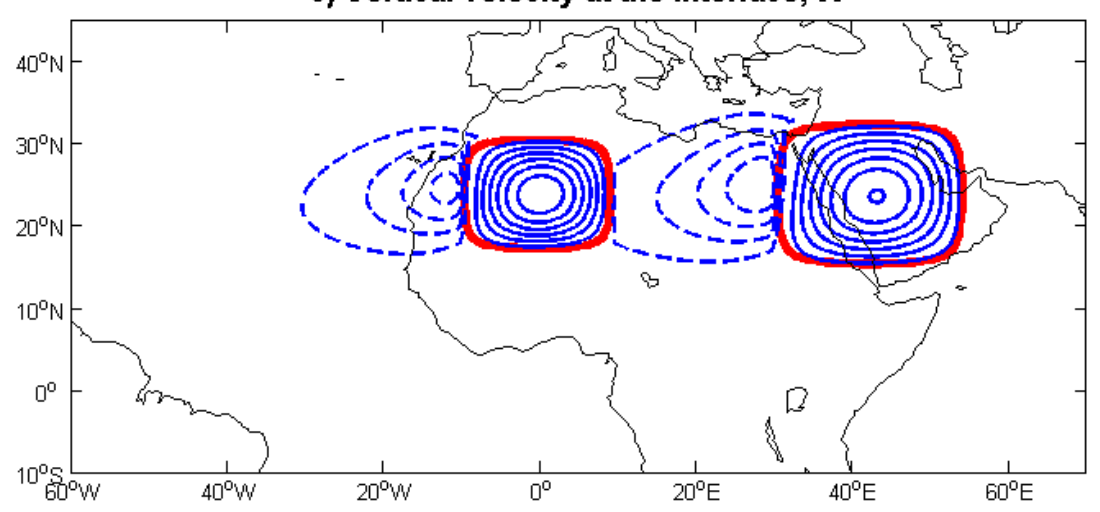

d) Lower-level winds $\& \phi_{2}$

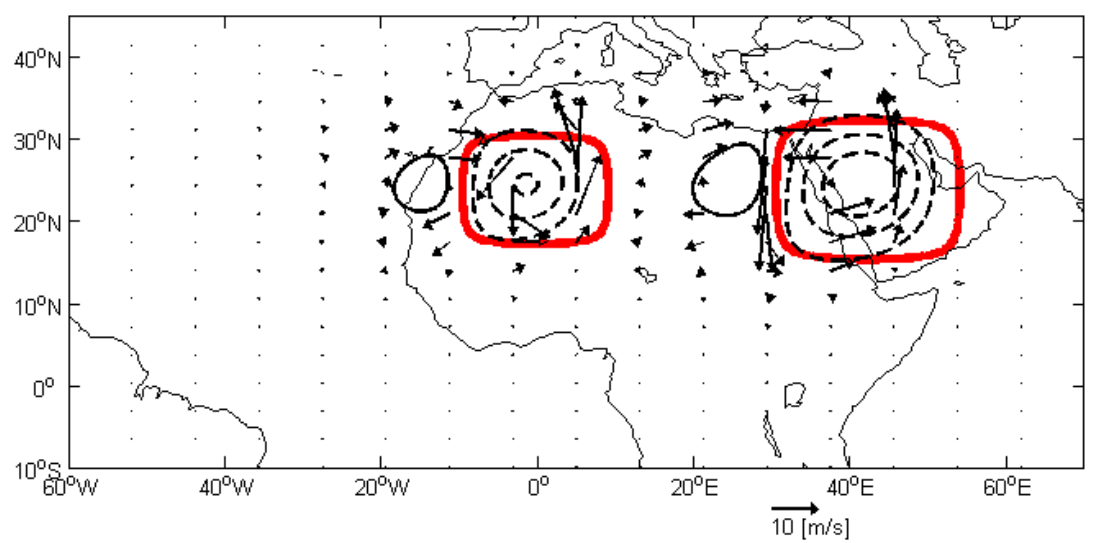

Figure 9: Same as Fig. 5, but in summer, $Q_{S H L}$ and $Q_{A H L}$ red contour, and $\Delta \phi=10[\mathrm{~m}]$ in layer 1 and 2. 
a) Coriolis parameter

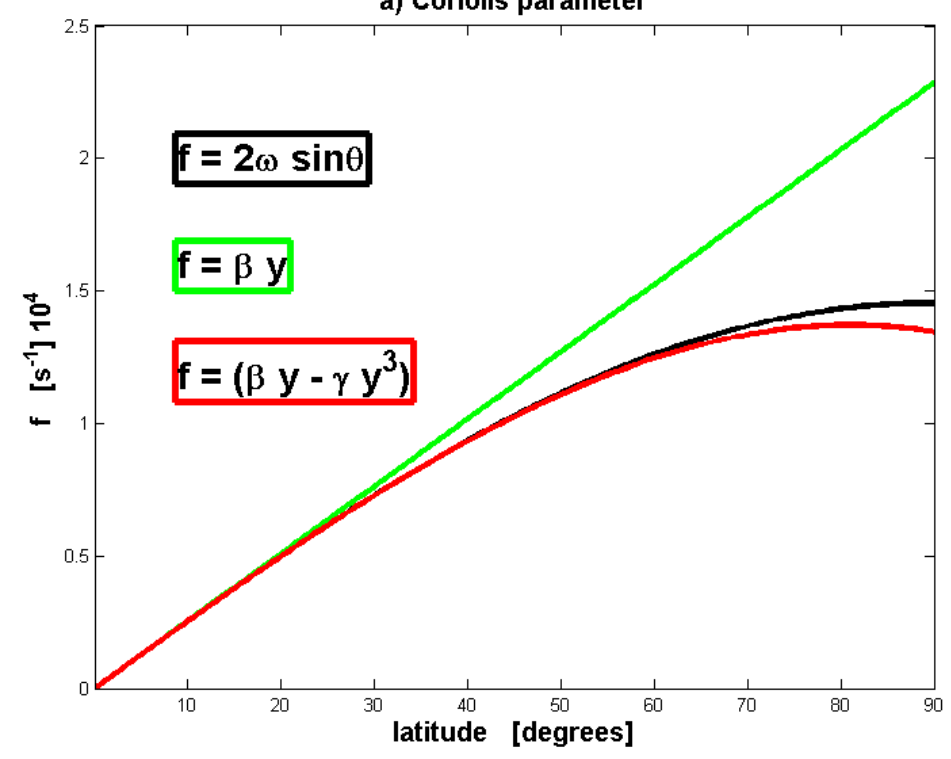

b) Relative amplitude of the $y$-correction
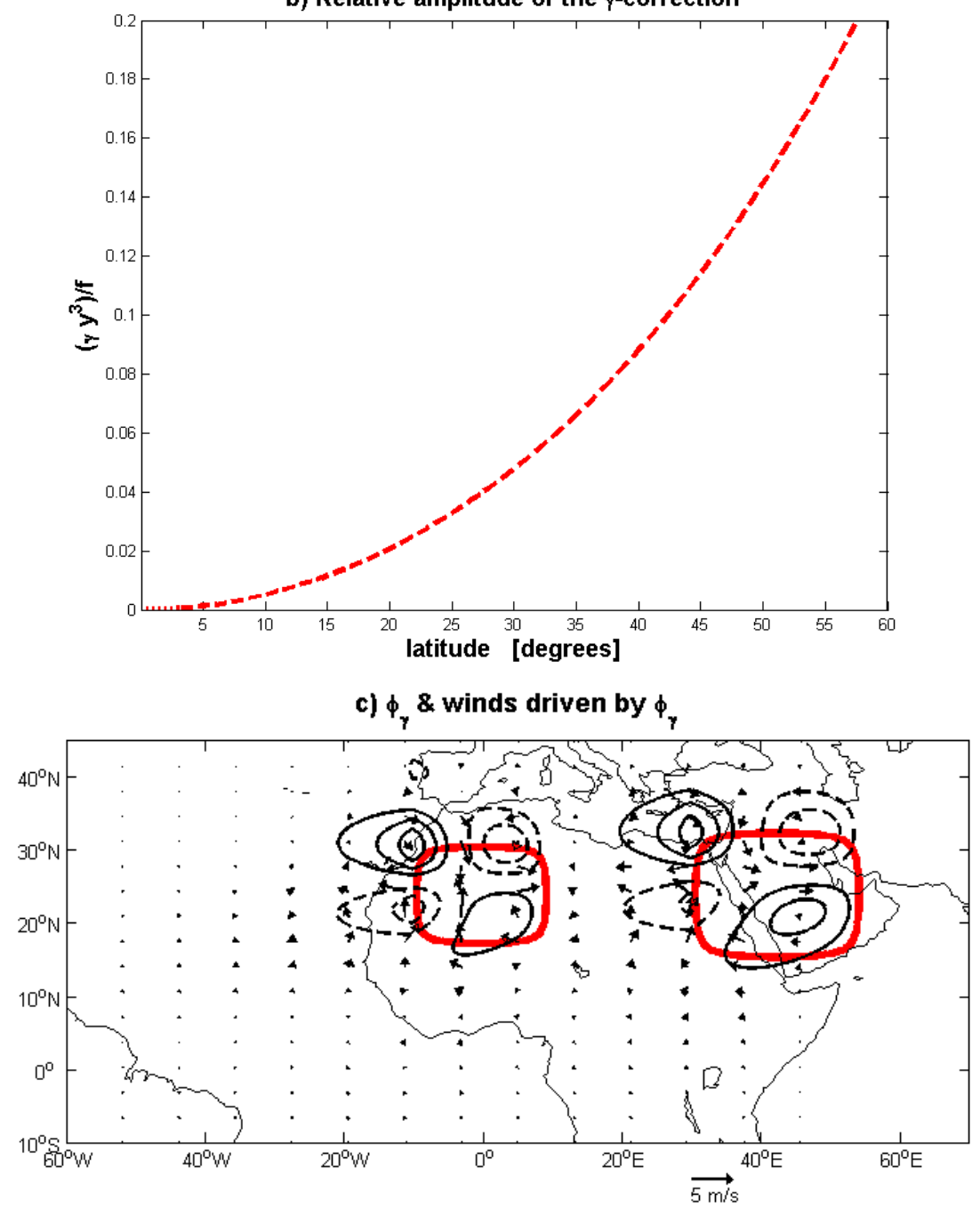

Figure 10: a) Coriolis parameter as a function of latitude. b) Its $\gamma$-correction (dash red). c) Winds and pressure perturbation related to $\gamma$-correction to the $\beta$-plane; $\Delta \phi_{\gamma}=2.5[\mathrm{~m}]$. 
a) Barotropic mode driven by the lid reaction, $\phi_{\text {Lid }}$

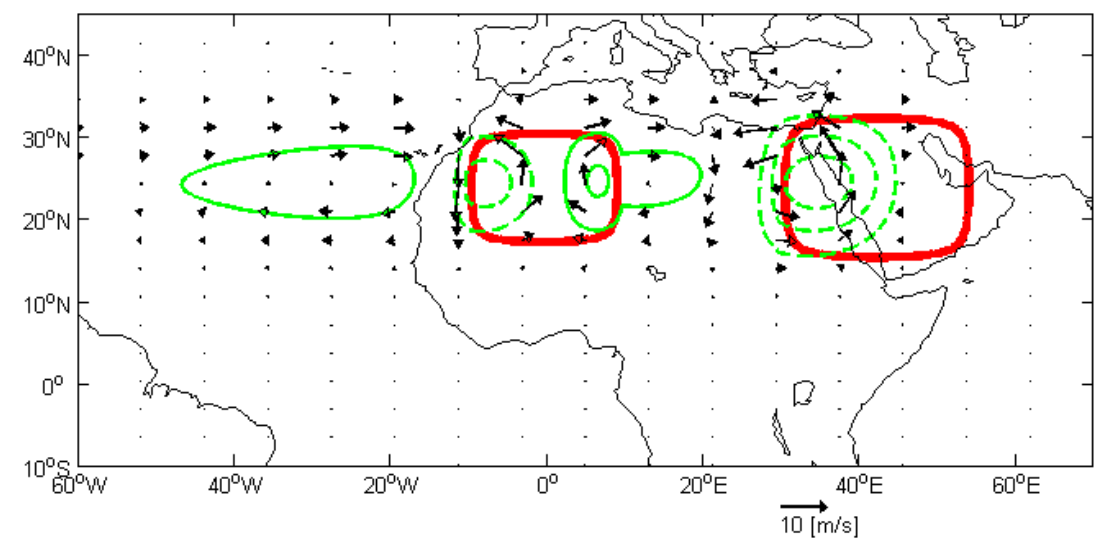

b) Upper-level winds $\& \phi_{1}$

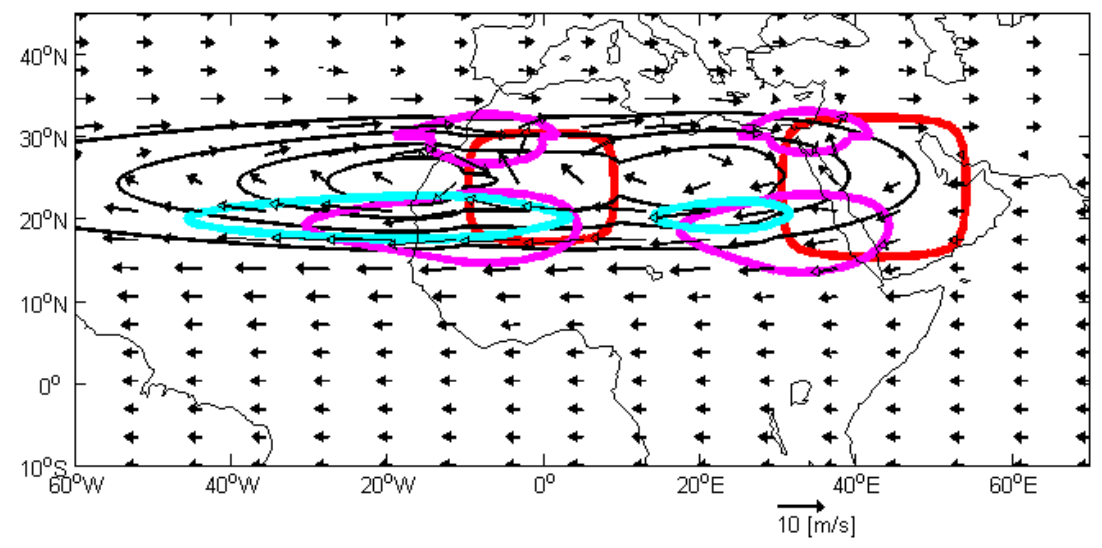

c) Vertical velocity at the interface, $W$

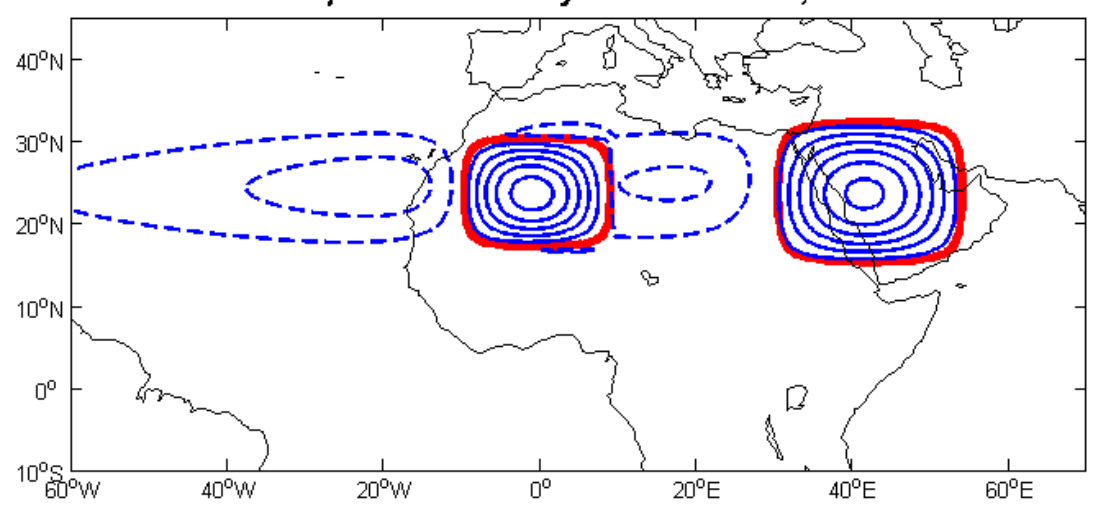

d) Lower-level winds $\& \phi_{2}$

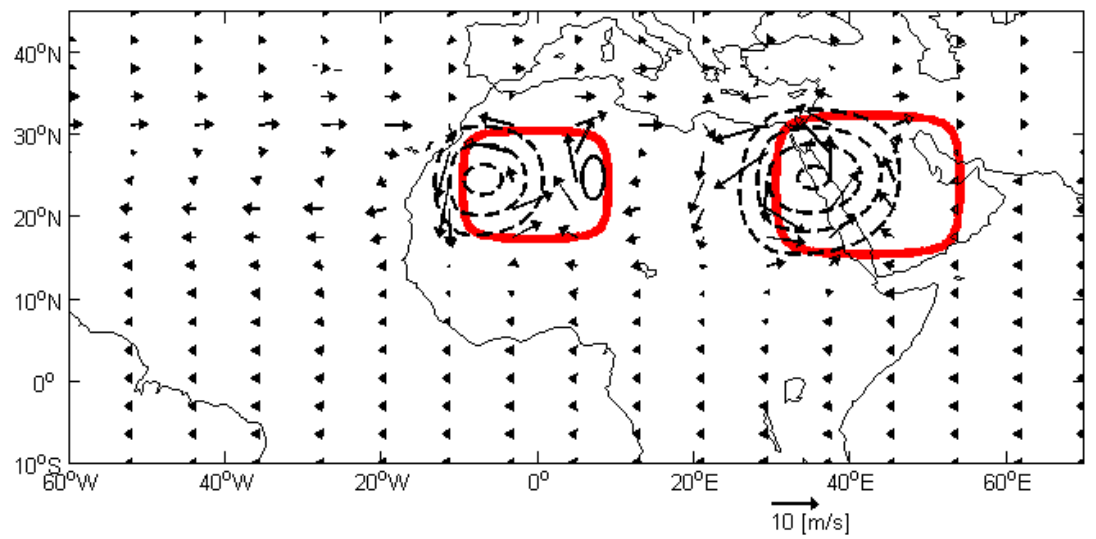

Figure 11: Same as Fig. 8, but in the presence of ambient winds. 


\section{a) Upper-level winds $\& \phi_{1}$}

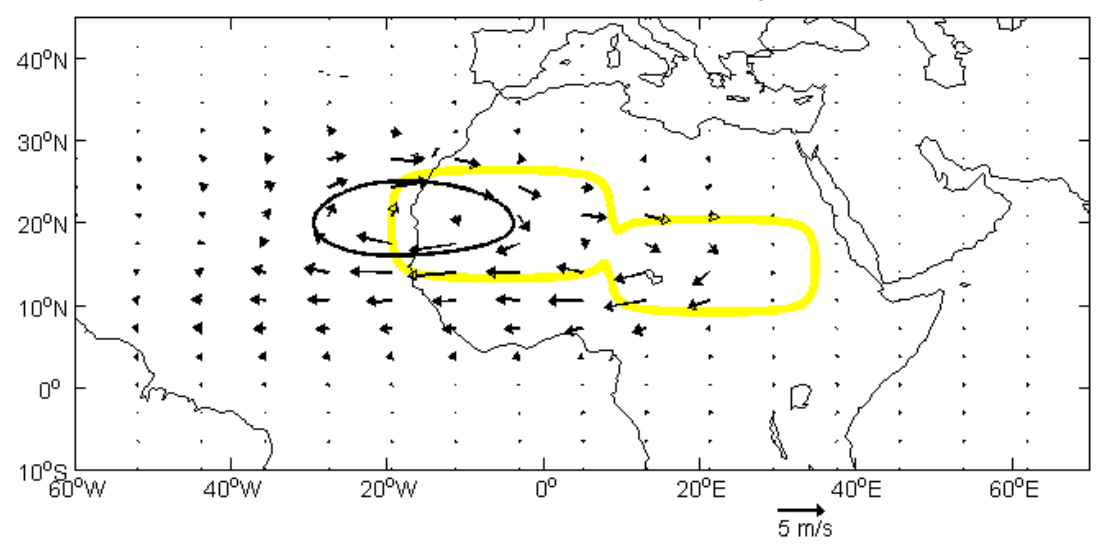

b) Upper-level winds $\& \phi_{1}$

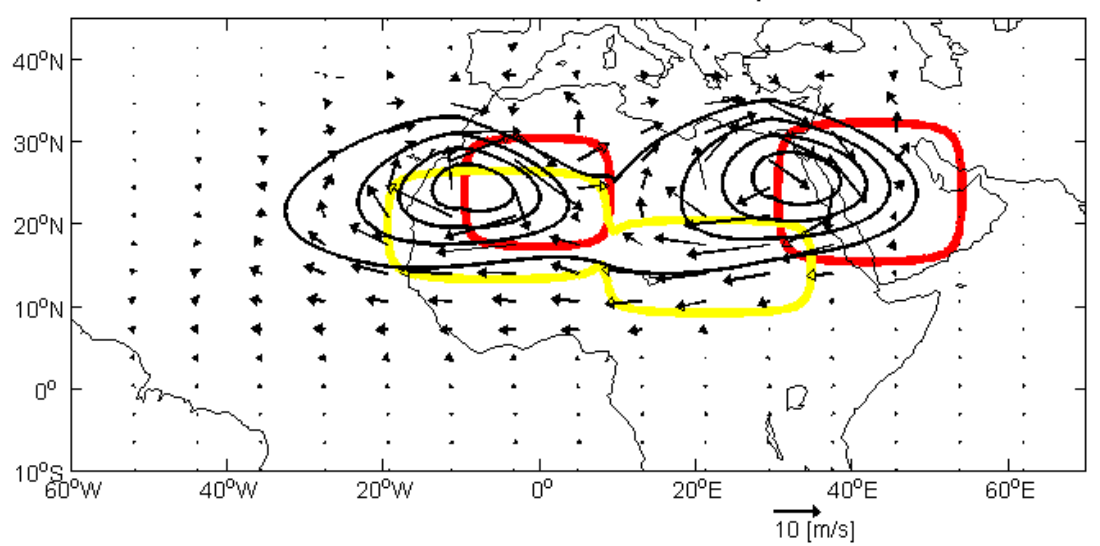

Figure 12: a) Upper-level winds driven by desert dust warming, $Q_{D D W}$ yellow contour, $\Delta \phi_{1}=5$ [m]. b) Same as a), but winds driven by, $Q_{D D W}$ yellow contour, $Q_{S H L}$ and $Q_{A H L}$ red contour. $\Delta \phi_{1}=15[\mathrm{~m}]$ 
a) Barotropic mode driven by $\phi_{\text {Lid }}$

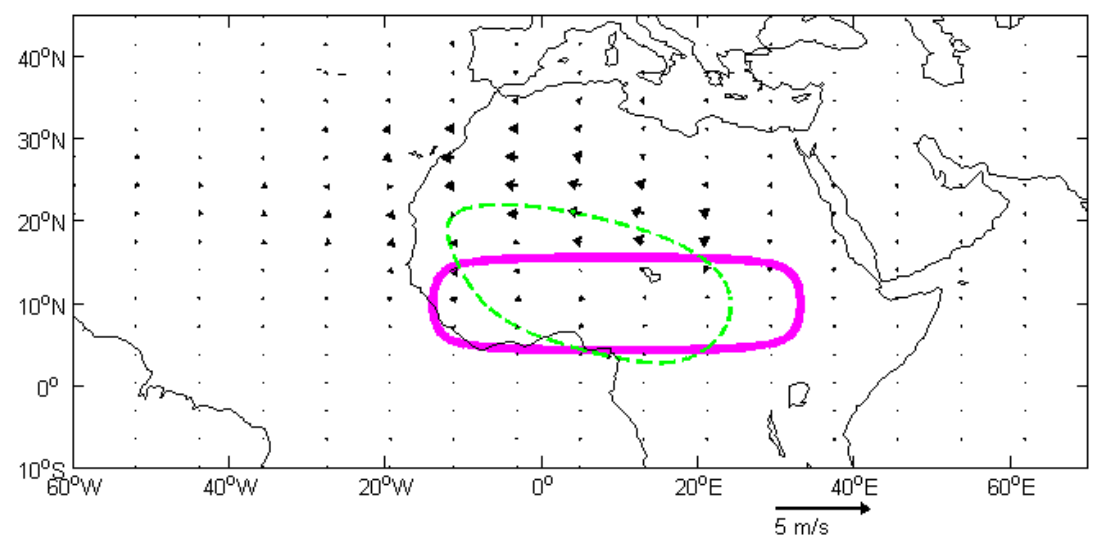

b) Upper-level winds $\& \phi_{1}$

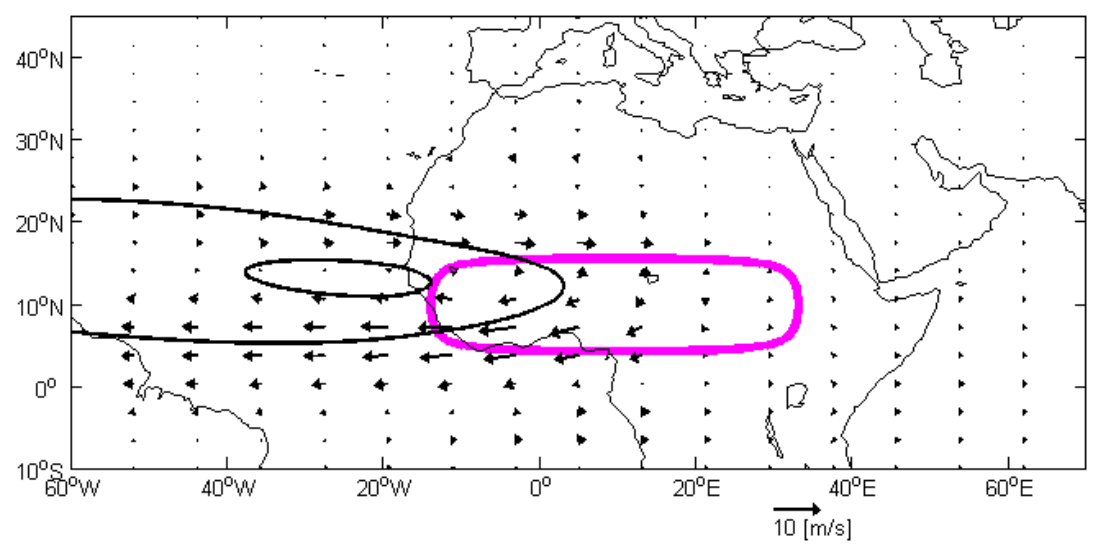

c) Vertical velocity at the Interface, $W$

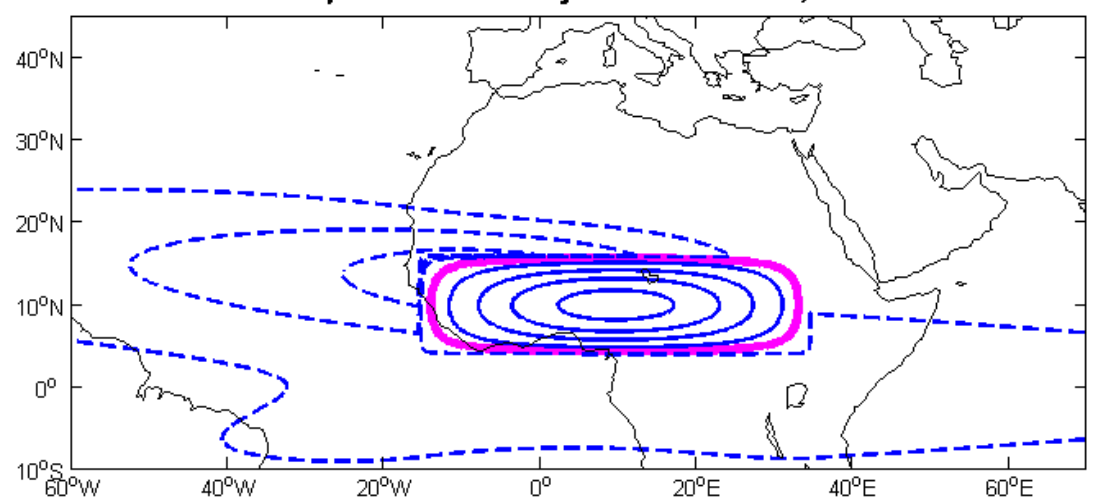

d) Lower-level winds $\& \phi_{2}$

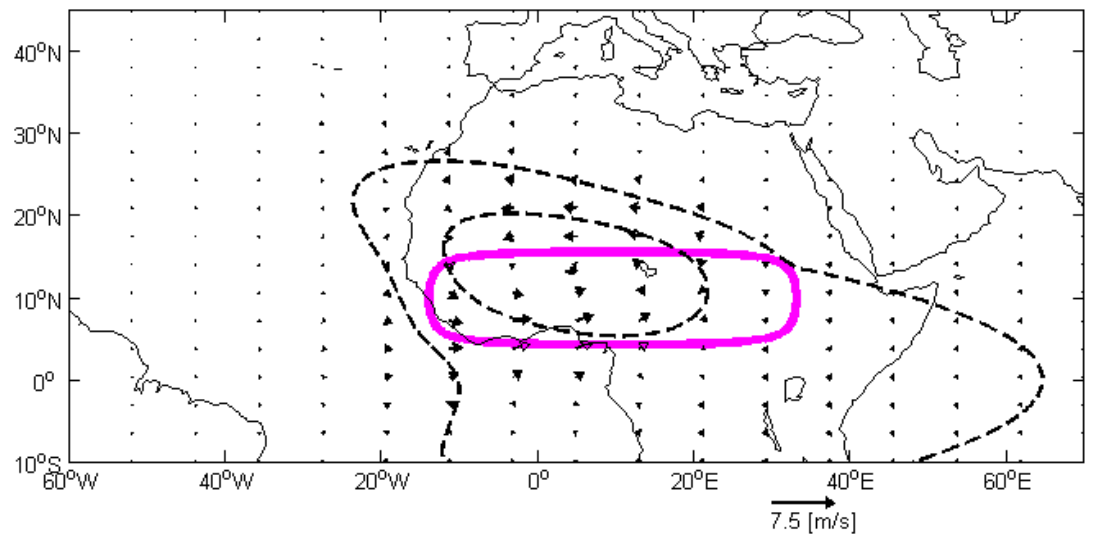

Figure 13: Monsoonal winds and vertical velocities, $Q_{W A M}$ magenta contour. $\Delta \phi_{L i d}=\Delta \phi_{1}=\Delta \phi_{2}=5$ [m], upwelling $\Delta W=3$ $[\mathrm{mm} / \mathrm{s}]$ and downwelling $\Delta W=0.1[\mathrm{~mm} / \mathrm{s}]$. 
a) Upper-level winds

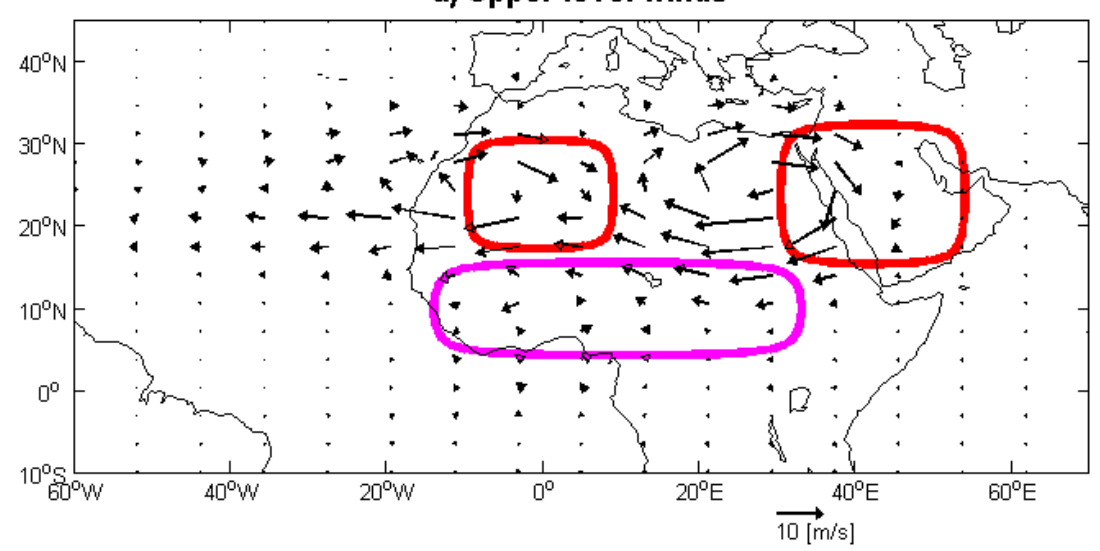

b) Lower-level winds

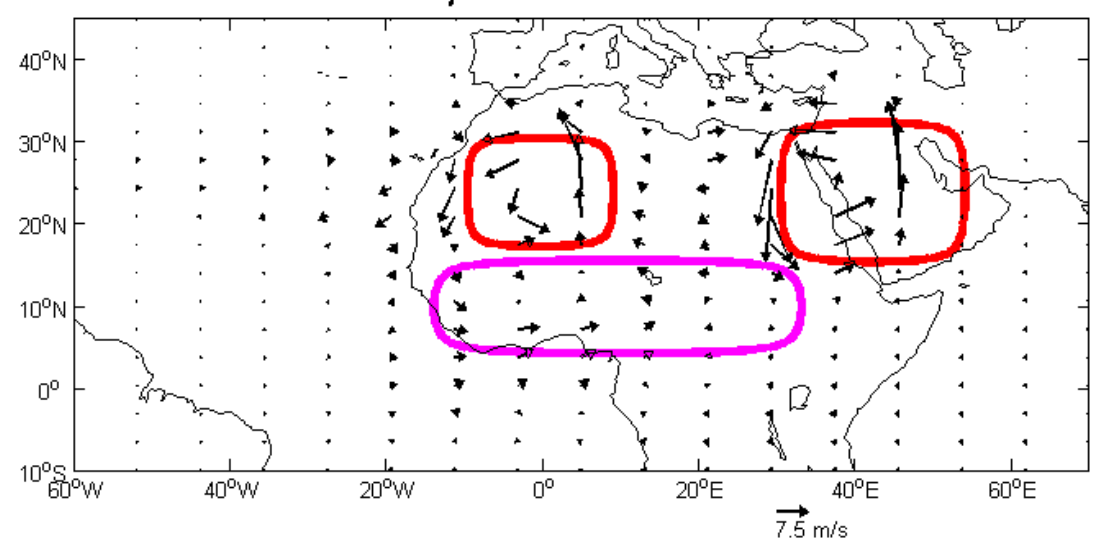

Figure 14: Winds in the lower half of the troposphere driven by the West African monsoon and by the desert lows, $Q_{W A M}$, magenta contour, $Q_{S H L}$ and $Q_{A H L}$ red contour. a) Upper-level winds. b) Lower-level winds. 